\title{
Membrane-organizing protein moesin controls Treg differentiation and antitumor immunity via TGF- $\beta$ signaling
}

\author{
Ephraim A. Ansa-Addo, ${ }^{1}$ Yongliang Zhang, ${ }^{1}$ Yi Yang, ${ }^{1}$ George S. Hussey, ${ }^{2}$ Breege V. Howley, ${ }^{2}$ Mohammad Salem, ${ }^{1}$ \\ Brian Riesenberg, ${ }^{1}$ Shaoli Sun, ${ }^{3}$ Don C. Rockey, ${ }^{4}$ Serhan Karvar, ${ }^{4}$ Philip H. Howe, ${ }^{2}$ Bei Liu, ${ }^{1}$ and Zihai Li' \\ ${ }^{1}$ Department of Microbiology and Immunology, Hollings Cancer Center, ${ }^{2}$ Department of Biochemistry and Molecular Biology, ${ }^{3}$ Department of Pathology and Laboratory Medicine, and ${ }^{4}$ Division of \\ Gastroenterology and Hepatology, Department of Medicine, Medical University of South Carolina, Charleston, South Carolina, USA.
}

\begin{abstract}
Moesin is a member of the ezrin-radixin-moesin (ERM) family of proteins that are important for organizing membrane domains and receptor signaling and regulating the migration of effector $\mathrm{T}$ cells. Whether moesin plays any role during the generation of TCF- $\beta$-induced Tregs (iTregs) is unknown. Here, we have discovered that moesin is translationally regulated by TCF- $\beta$ and is also required for optimal TCF- $\beta$ signaling that promotes efficient development of iTregs. Loss of moesin impaired the development and function of both peripherally derived iTregs and in vitro-induced Tregs. Mechanistically, we identified an interaction between moesin and TCF- $\beta$ receptor II (T $\beta$ RII) that allows moesin

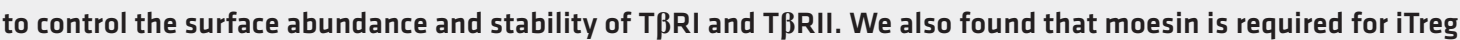
conversion in the tumor microenvironment, and the deletion of moesin from recipient mice supported the rapid expansion of adoptively transferred $C D 8^{+} \mathrm{T}$ cells against melanoma. Our study establishes moesin as an important regulator of the surface abundance and stability of TßRII and identifies moesin's role in facilitating the efficient generation of iTregs. It also provides an advancement to our understanding about the role of the ERM proteins in regulating signal transduction pathways and suggests that modulation of moesin is a potential therapeutic target for Treg-related immune disorders.
\end{abstract}

\section{Introduction}

Moesin is a member of the ezrin-radixin-moesin (ERM) protein family, primarily expressed in the cytoplasm and concentrated in actin-rich cell surface structures. ERM proteins contain an aminoterminal FERM (4.1 protein, ezrin, radixin, moesin) domain that binds transmembrane proteins and a carboxy-terminal tail that links F-actin (1). The functions of ERM proteins are regulated by an intramolecular interaction between the $\mathrm{N}$-terminal FERM domain and the C-terminal tail domain. ERM proteins exist in 2 states: a closed/inactive state in which the FERM domain is tightly bound to the tail domain, masking the binding sites for other molecules; and a phosphorylated active/opened form that tethers between actin and receptors on the plasma membrane (1). Moesin is upregulated in multiple human cancers, including breast cancers (2), prostate (3), pancreatic (4), and lung and melanoma (5), and it is the dominant ERM protein in lymphocytes (6), where it has been implicated in the egress of $\mathrm{T}$ and $\mathrm{B}$ cells from the secondary lymphoid organs (7). No roles for moesin in $\mathrm{CD}^{+} \mathrm{T}$ cell specification have been defined.

Regulatory $\mathrm{T}$ cells (Tregs) are generated either in the thymus, called thymic Tregs (tTregs) (8), or in peripheral tissues, called peripherally derived inducible Tregs (pTregs), which dif-

Conflict of interest: The authors have declared that no conflict of interest exists

Submitted: June 27, 2016; Accepted: January 17, 2017

Reference information: J Clin Invest. 2017;127(4):1321-1337.

https://doi.org/10.1172/JCl89281. ferentiate from naive $\mathrm{T}$ cell precursors (9). In addition, Tregs can also be differentiated in vitro upon $\mathrm{T}$ cell receptor (TCR) stimulation in the presence of TGF- $\beta$ and IL- 2 from naive CD $4^{+}$ $\mathrm{T}$ cells, referred to as in vitro-induced Tregs (iTregs). These Tregs express the master transcription factor FOXP3 and are critical for suppressing a broad range of undesired immune responses in order to maintain immune homeostasis and tolerance (8). Thus, Treg-mediated immune suppression becomes an obvious mechanism that tumors, considered "self" tissues, can co-opt in order to limit inflammation and evade immunosurveillance. Indeed, Tregs are readily detectable in various tumors, and their numbers are evidently increased in multiple cancers. How iTregs are maintained under increased TGF- $\beta$ conditions such as in a tumor setting is less clear.

TGF- $\beta$ regulates the proliferation and differentiation of many cell types by controlling the expression of multiple target genes. TGF- $\beta$ signaling is initiated at the cell membrane through type I (T $\beta R I)$ and type II (T $\beta$ RII) TGF- $\beta$ receptors, which activate the SMAD2/3 pathway and non-SMAD signaling pathways, including PI3K/Akt, p38 MAPK, and ERK pathways (10). In transforming epithelial cells, TGF- $\beta$ signaling pathologically promotes the acquisition of a more migratory, mesenchymal phenotype, known as epithelial-mesenchymal transition (EMT), via induction of many target genes. In T cells, TGF- $\beta$ signaling is important for FOXP3 expression by induced Tregs and promotes the generation of proinflammatory Th17 cells, but negatively con- 
A

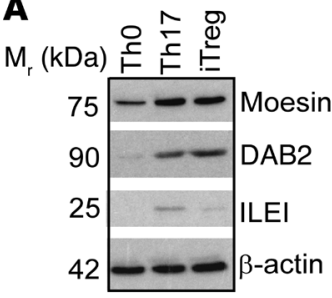

B

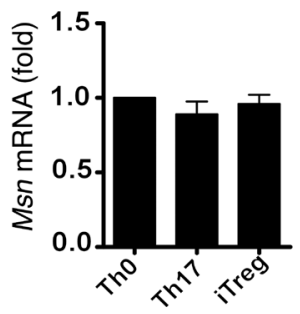

$\mathbf{E}$

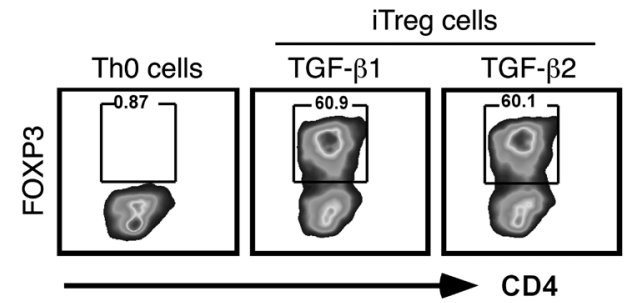

G

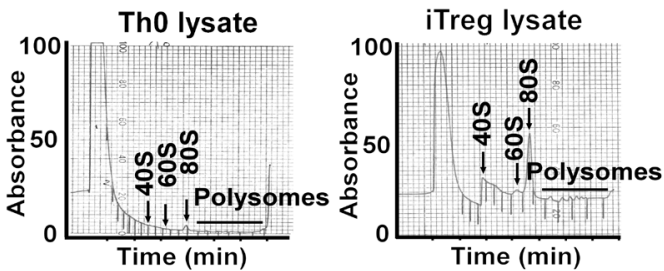

H

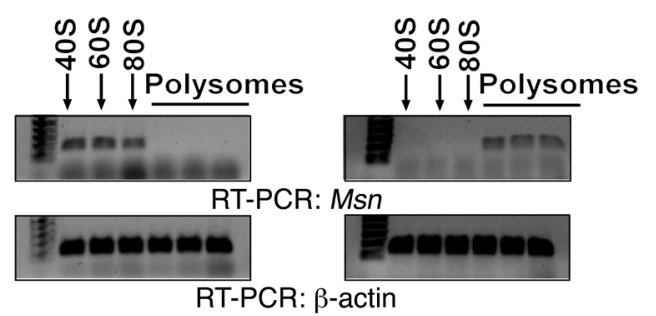

$\mathbf{K}$

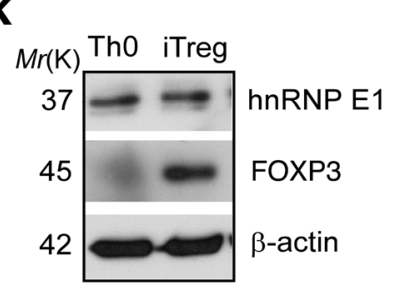

C

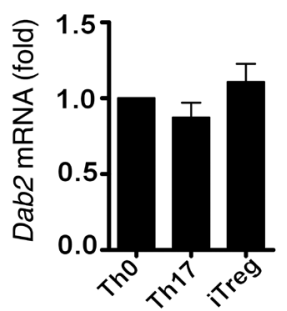

$\mathbf{F}$

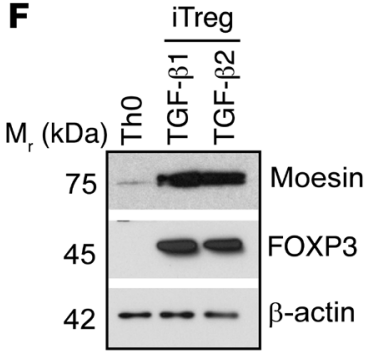

\section{I}
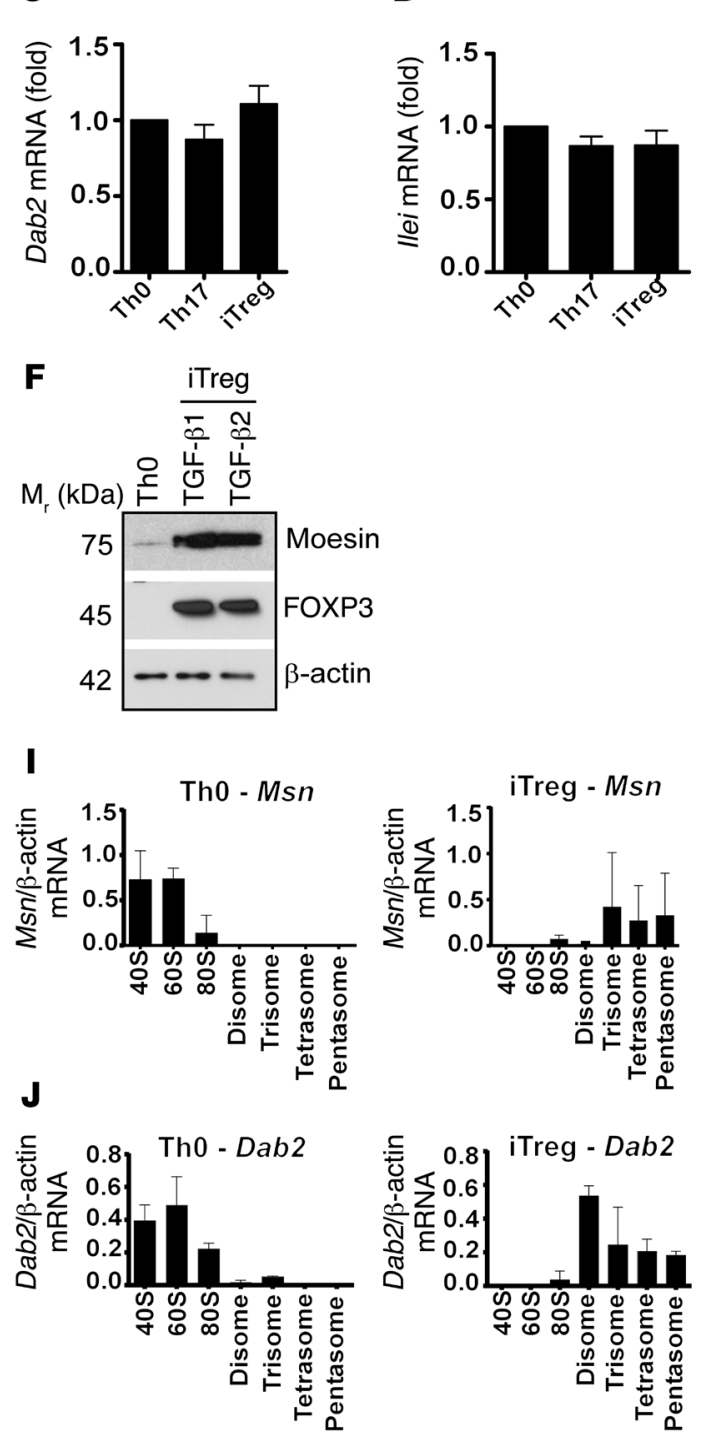
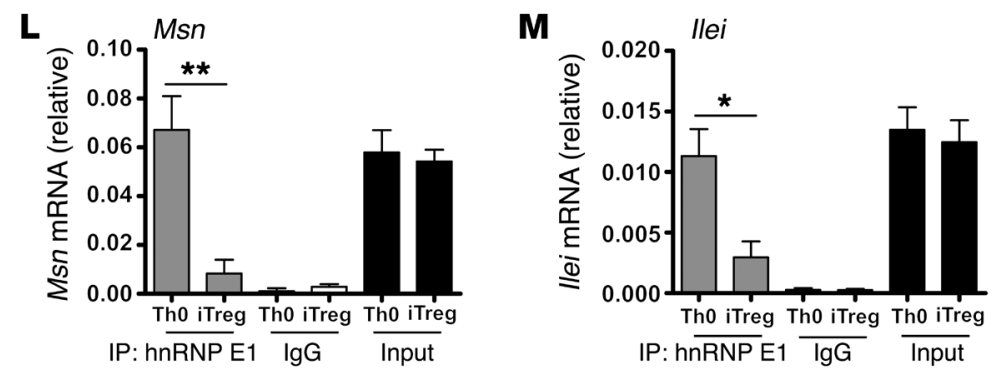

Figure 1. TGF- $\beta$ translationally upregulates moesin mRNA expression within iTregs. Primary $C D 4^{+} C D 25^{-} T$ cells were isolated from $C 57 B L / 6$ mice and stimulated with plate-bound anti-CD3 and soluble anti-CD28, IL-2, anti-IFN- $\gamma$, and anti-IL- 4 without TCF- $\beta$ for Th0 cells; or with IL-6 (50 ng/mI) and TCF- $\beta$ $(5 \mathrm{ng} / \mathrm{ml})$ for Th17; and TGF- $\beta 1$ (10 ng/ml) for iTregs for 3 days. (A) Immunoblotting of moesin, DAB2, and ILEl in T cells. (B-D) Fold mRNA of Msn (B), Dab2 (C), and Ilei (D) in Th0 and Th17 cells and iTregs. (E and F) Flow cytometry analysis (E) and immunoblot of FOXP3 expression (F) in iTregs using TGF- $\beta 1$ or TGF- $\beta 2$. (G and H) Polyribosome profiling (G) and RT-PCR (H) of Msn mRNA from monosomal fractions (40S, 60S, and 80S) in Th0 cells to the translating polysomal fractions in iTregs. (I and J) Quantitative RT-PCR of Msn (I) and Dab2 (J) mRNAs from the monosomal to polysomal fractions in iTregs. (K) Immunoblot of hnRNP E1, FOXP3, and $\beta$-actin in ThO cells and iTregs. (L and $\mathbf{M}$ ) RNA immunoprecipitation (RIP) of Msn and Ilei transcripts in Th0 cells and iTregs. Data represent the mean \pm SD of 3 independent experiments performed in triplicate (B-D, $\mathbf{I}$, and $\mathbf{J}$ ), or 2 independent experiments performed in triplicate $(\mathbf{L}$ and $\mathbf{M}) .{ }^{*} P<0.05,{ }^{* *} P<0.01$ by Student's $t$ test. 
A

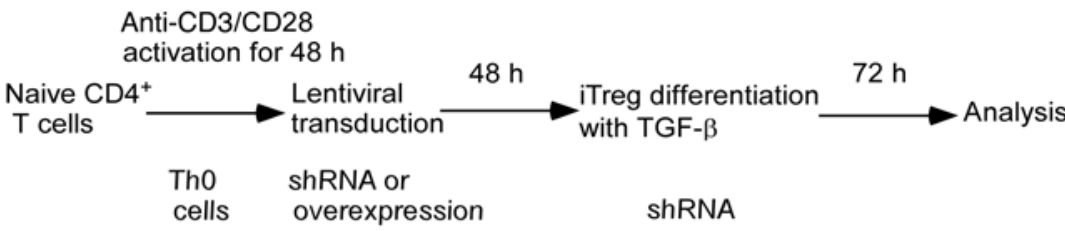
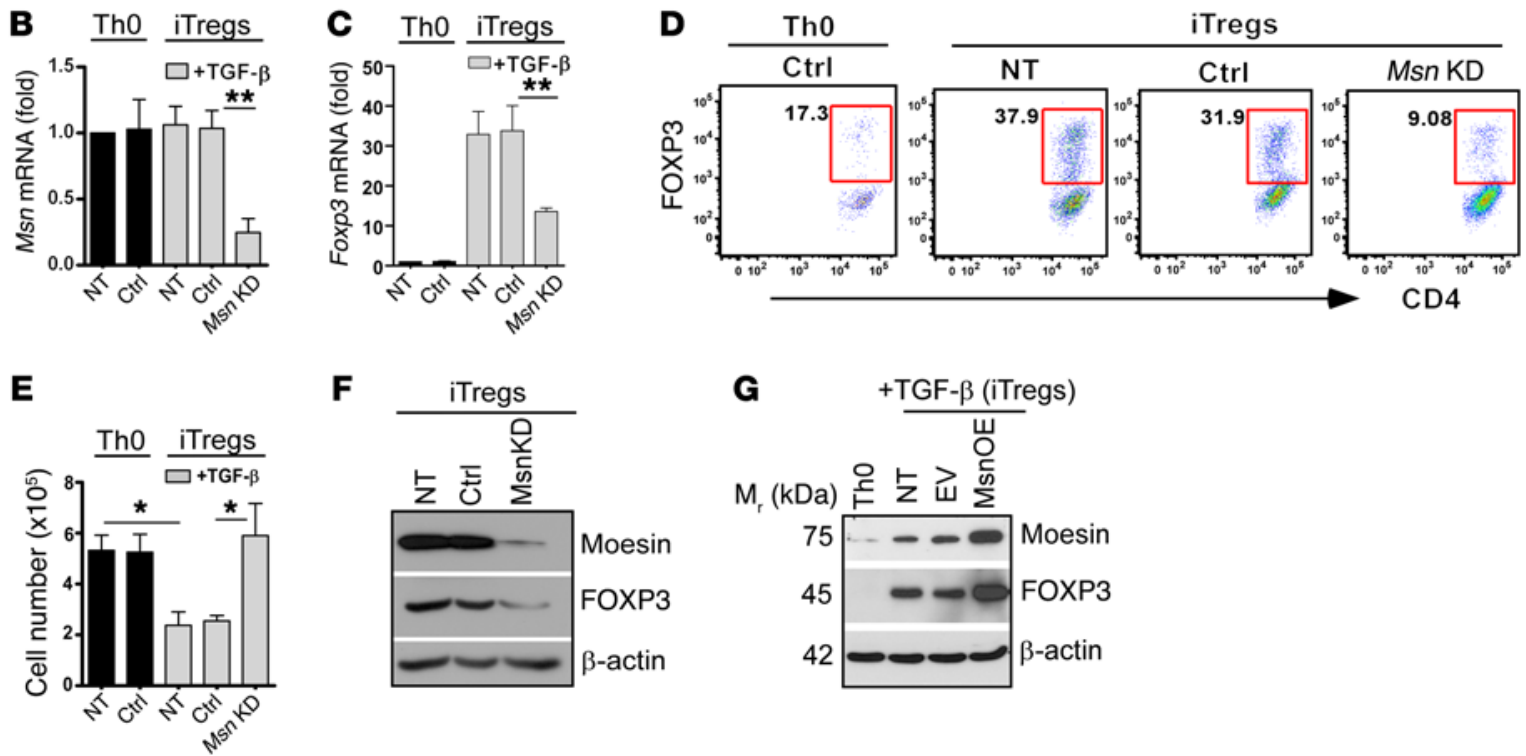

Figure 2. Moesin promotes FOXP3 induction in TGF- $\beta$-mediated iTregs. (A) Lentiviral shRNA transduction steps to generate moesin knockdown (Msn KD) T cells. (B and C) Quantitative RT-PCR of total Msn (B) and Foxp3 (C) mRNA expression in Th0 cells and iTregs not transduced (NT) or transduced with control vector (Ctrl) or Msn shRNA. (D) Representative flow cytometry analysis of percentage FOXP3 expression in the transduced cells shown in B and C. (E) Assessment of cell numbers by trypan blue exclusion in iTreg differentiation culture. Data represent the mean \pm SD of at least 3 independent experiments performed in triplicate (B, C, and E). ${ }^{*} P<0.05,{ }^{* *} P<0.01$ by Student's $t$ test. (F) Immunoblot of moesin and FOXP3 in WT CD4 $4^{+}$CD25- T cells first differentiated into iTregs in vitro, and then transduced with lentivirus shRNA or control. Representative data are shown. (G) Moesin overexpression (Msn OE) in primary CD4 ${ }^{+} \mathrm{CD}_{25} \mathrm{~T}$ cells and FOXP3 expression in iTregs. EV, empty vector. Data shown are representative of at least 3 independent experiments.

trols the Th1 and Th2 subsets (11). We previously demonstrated a TGF- $\beta$-mediated translational mechanism in transforming epithelial cells, whereby TGF- $\beta$ induces expression of selective EMT genes by liberating target mRNAs from a heterogeneous nuclear ribonucleoprotein E1-containing (hnRNP E1-containing) translation repression complex (12). However, the roles of the TGF- $\beta$-hnRNP E1 molecular circuit in regulating iTreg biology are completely unknown.

In this study, we unveil an unrecognized post-transcriptional mechanism involved in iTreg development. Moesin repression by hnRNP E1 is relieved by TGF- $\beta$, and it contributes important signaling roles during iTreg differentiation. The loss of moesin caused a significant reduction in the generation of iTregs due in part to a marked inefficiency in TGF- $\beta$ signaling. The reduced TGF- $\beta$ signaling and fewer FOXP3 ${ }^{+}$iTregs in these mice supported the rapid expansion and persistence of antigen-specific Pmel-1 CD8 ${ }^{+} \mathrm{T}$ cells conferring a delayed tumor recurrence in a mouse model of melanoma. Finally, we demonstrate, for the first time to our knowledge, that moesin associates with TRRII and controls its surface expression and stability to promote efficient generation of iTregs, suggesting the modulation of moesin as a potential therapeutic target for the treatment of Tregrelated immune diseases.

\section{Results}

TGF- $\beta$ translationally upregulates moesin expression in iTregs. In nontransformed epithelial cells, many TGF- $\beta$-mediated EMT genes, including disabled-2 homolog (Dab2) and interleukin-like inducer (Ilei, also known as Fam3c), are translationally repressed by hnRNP E1 via direct binding to a 33 -nucleotide TGF- $\beta$-activated translation (BAT) element in the $3^{\prime}$-UTR (12). TGF- $\beta$ activation leads to hnRNP E1 phosphorylation at Ser 43 by protein kinase B $\beta / A k t 2$, causing its release from the target transcript and subsequent translation of the mRNA (13). Although TGF- $\beta$ plays important roles during iTreg generation, little is known about the post-transcriptional mechanisms by which it exerts some of its effects on T cells. Previous results from a combined polyribosome profiling and Affymetrix array identified selective EMT genes that are translationally upregulated by TGF- $\beta$ (14). Since TGF- $\beta$ is important for the generation of iTregs, we hypothesized that in naive $\mathrm{CD} 4^{+} \mathrm{T}$ cells, hnRNP E1 selectively binds to and stalls the translation of EMT genes, which are also involved in iTreg differentiation (Supplemental Figure 1A; supplemental material available online with this article; https:// doi.org/10.1172/JCI89281DS1). Indeed, a number of TGF- $\beta$ induced EMT genes, such as aryl hydrocarbon receptor (Ahr), disabled-2 homolog (Dab2), and Ets-1, promote cancer metastasis and also regulate various aspects of Treg cell biology (15-17). 
A

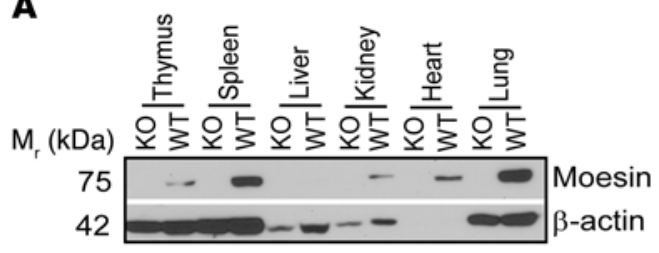

B

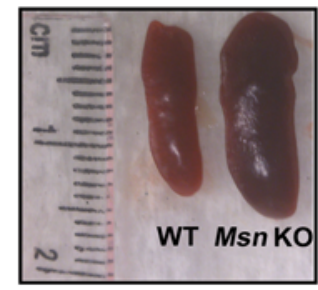

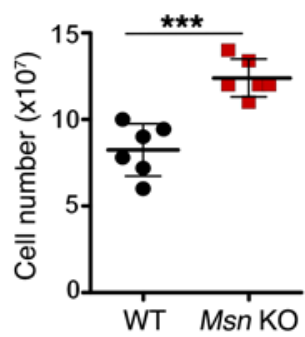

C
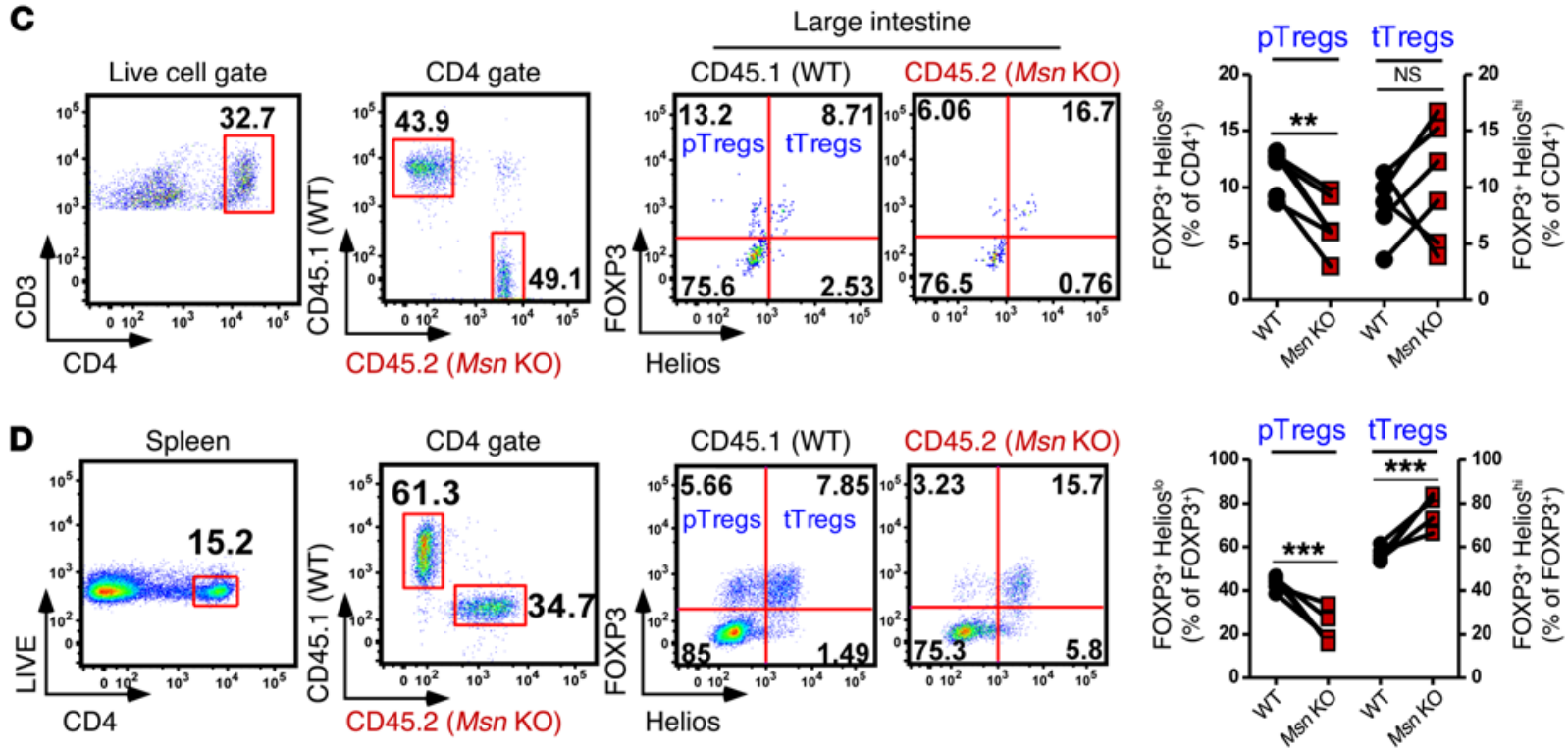

Thymus
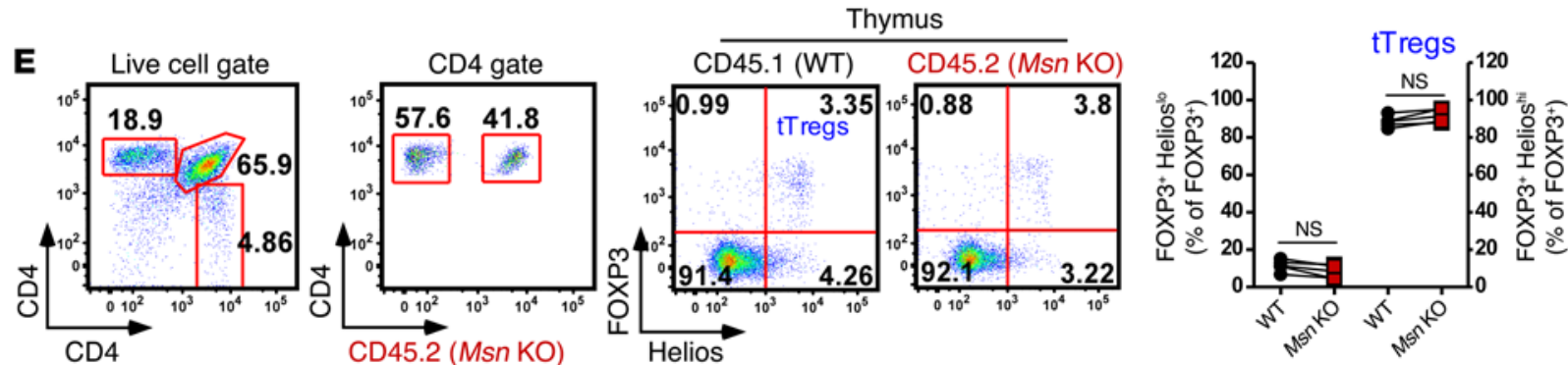

Figure 3. Cell-intrinsic moesin controls pTregs but is dispensable for tTreg generation. (A) Immunoblot of moesin knockout (KO or Msn KO) in multiple organs of mice. (B) Representative enlarged spleen size and increased cell number as observed in Msn KO mice. (C-E) Reconstituted 1:1 mix of WT (CD45.1, black) and Msn KO (CD45.2, red) bone marrow chimeric mice. Flow cytometry analysis of pTregs (FOXP3+Helios ${ }^{10}$ ) in the large intestine (C), spleen (D), and thymus (E) of mice reconstituted for 8-10 weeks. Data are reported as the mean \pm SEM (B-E). ${ }^{* *} P<0.01,{ }^{* * *} P<0.001$ by Student's $t$ test. $n=6$ per group (B-E).

To determine the roles of the TGF- $\beta$-hnRNP E1 molecular circuit in iTreg biology, we profiled the expression level of selective target genes including moesin (Msn), Dab2, and Ilei at the mRNA and protein levels in anti-CD3/anti-CD28-activated splenic $\mathrm{CD}^{+} \mathrm{CD} 25^{-} \mathrm{T}$ cells (Th0 cells), Th17 cells, and iTregs. These genes were demonstrated previously to be translationally regulated by the TGF- $\beta$-hnRNP E1 molecular circuit in transforming epithelial cells $(12,18)$. Although the protein expression of moesin, DAB2, and ILEI was strongly upregulated in both Th17 cells and iTregs (Figure 1A), we found little or no change in the expression of Msn, Dab2, and Ilei mRNAs comparing with ThO cells (Figure 1, $\mathrm{B}-\mathrm{D})$. These data suggested post-transcriptional regulation of $M s n$, Dab2, and Ilei by TGF- $\beta$ in Th17 cells and iTregs as in transforming epithelial cells. We focused on iTregs because of their preferential requirement for TGF- $\beta$ and detected similar FOXP3 induction with TGF- $\beta 1$ and TGF- $\beta 2$ (Figure 1, E and F). We next confirmed post-transcriptional control of Msn and Dab2 transcripts in T cells by polyribosome profiling as reported previously (ref. 14 and Figure 1G) and found a shift of the Msn transcript from the monosomal to polysomal fractions in iTregs, indicative of active translation (Figure 1, H and I). Additionally, Dab2, reported as a FOXP3 target in Tregs, was also enriched in polysome fractions of iTregs (Figure $1 \mathrm{~J}$ and ref. 17). We focused on moesin as its role in iTreg speciation in completely unknown. To ascertain whether the TGF- $\beta$-hnRNP E1 circuit regulates Msn transcript in iTregs, we assessed total hnRNP E1 expression in ThO cells and iTregs by immunoblotting and found no difference (Figure 1K). RNA immunoprecipitation analysis using anti-hnRNP E1 antibody in both ThO cells and iTregs showed no association between hnRNP E1 and either Foxp3 or p21 mRNAs (Supplemental Figure 1, B and C). However, Msn 
A

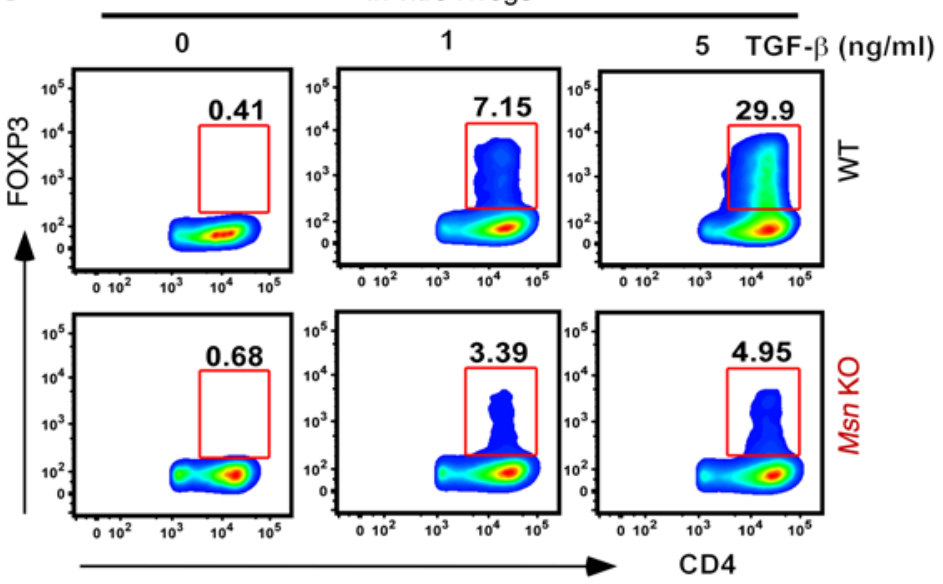

B

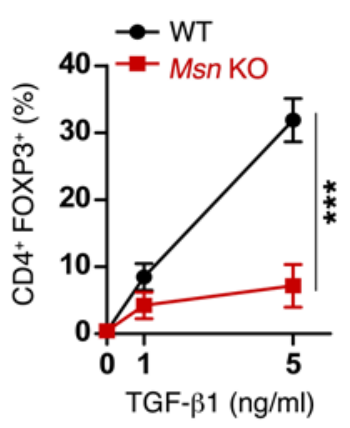

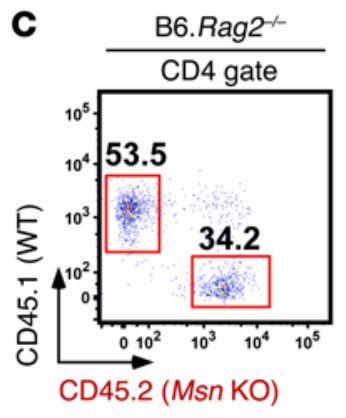
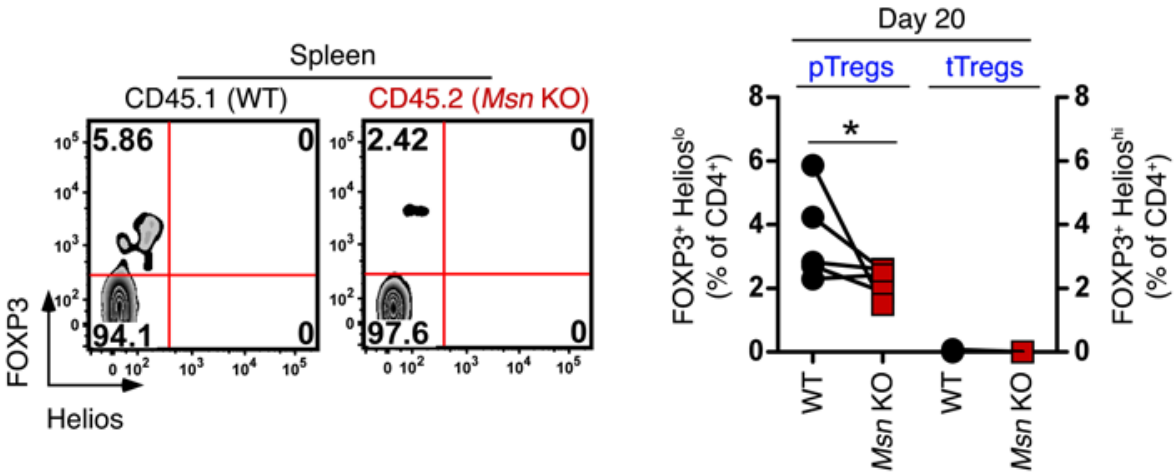

Figure 4. Cell-intrinsic moesin promotes efficient conversion of naive $\mathbf{C D 4}^{+} \mathbf{T}$ cells into induced Tregs. (A and B) Representative flow cytometry analysis (A) and quantification (B) of FOXP3 expression in primary CD4 ${ }^{+} C D 25^{-}$T cells from the spleen of WT or Msn KO mice cultured in vitro for 5 days with IL-2, anti-CD3/CD28, anti-IL-4, and anti-IFN- $\gamma$, plus varying concentrations of TCF- $\beta$. (C) Eight to ten weeks after bone marrow reconstitution with 1:1 mix of WT (CD45.1, black) and Msn KO (CD45.2, red) bone marrow, mice were euthanized, and splenic CD4+CD25- T cells ( $2 \times 10^{6}$ per mouse) were isolated and

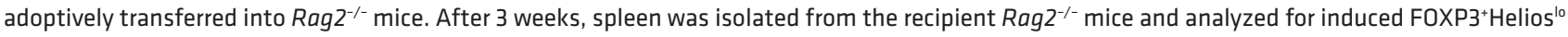
pTregs. Data represent the mean $\pm \mathrm{SD}$ of 3 independent experiments in triplicate (B) or the mean $\pm \mathrm{SEM}$ of 2 experiments (C). ${ }^{*} P<0.05,{ }^{* * *} P<0.001$ by Student's $t$ test. $n=5$ mice (C).

and Ilei transcripts associated with hnRNP E1 in ThO subsets and thus were repressed; but this interaction was lost in iTregs (Figure $1, \mathrm{~L}$ and $\mathrm{M})$. Taking these results together, we conclude that TGF- $\beta$ orchestrates a translational mechanism during the differentiation of naive $\mathrm{CD}^{+}{ }^{+} \mathrm{T}$ cells to iTregs.

Moesin is required for efficient generation of TGF- $\beta$-induced in vitro Tregs. The strong induction of moesin by TGF- $\beta$ prompted us to determine its roles during iTreg generation. To this end, we knocked down (KD) Msn in splenic murine $\mathrm{CD}^{+} \mathrm{T}$ cells using a lentiviral shRNA system (Figure 2A). Interestingly, Msn KD $\mathrm{CD} 4{ }^{+} \mathrm{CD} 25^{-} \mathrm{T}$ cells expressed less FOXP3 under Treg-inducing conditions (Figure 2, B-D) and resulted in increased cell numbers (Figure $2 \mathrm{E}$ ). We next differentiated primary $\mathrm{CD} 4{ }^{+} \mathrm{CD} 25^{-} \mathrm{T}$ cells to iTregs for 3 days in culture, and then transduced these iTregs with lentiviral shRNA to knock down Msn expression. Compared with nontransduced iTregs or scrambled control, Msn KD in iTregs resulted in a considerable reduction in FOXP3 expression (Figure $2 \mathrm{~F}$ ). This suggests that moesin is involved in maintaining the FOXP3 $^{+}$iTreg lineage. Consistently, overexpression of moesin in $\mathrm{CD} 4{ }^{+} \mathrm{CD} 25^{-} \mathrm{T}$ cells considerably augmented FOXP3 levels under Treg-inducing conditions (Figure $2 \mathrm{G}$ ). All together, these data suggest that moesin promotes efficient differentiation to $\mathrm{FOXP}^{+}$ iTregs and is also involved in maintenance of the lineage.

Cell-intrinsic moesin preferentially controls generation of FOXP3 ${ }^{+}$Helios $^{l o}$ pTregs, and knockout mice exhibit inflammation. To ascertain our in vitro findings, we generated moesin knockout (Msn KO) mice (Supplemental Figure 2A) using the conventional genetrapping system (Texas A\&M Institute for Genomic Medicine) and confirmed the near-total absence of moesin by immunoblotting (Figure 3A). Initial characterization of Msn KO mice maintained on a 129/B6 genetic background or backcrossed up to 3 generations did not reveal any apparent disease phenotypes. However, when backcrossed 6-8 generations to the C57BL/6 background, Msn KO mice were found to have splenomegaly and increased cellularity (Figure 3B). Phenotypic analysis of Msn KO mice revealed no apparent differences in the total number of cells in the thymus in comparison with WT littermates (Supplemental Figure 2, B and C). In contrast, the number of total $\mathrm{CD} 4^{+}$and $\mathrm{CD} 8^{+} \mathrm{T}$ cells was higher in the spleen and mesenteric lymph nodes (MLNs) of Msn KO mice compared with WT littermates (Supplemental Figure 2, D and E). Interestingly, $\mathrm{CD} 4^{+} \mathrm{T}$ cells isolated from the spleen of $M s n \mathrm{KO}$ mice presented an activated phenotype with more $\mathrm{CD} 4{ }^{+} \mathrm{CD} 62 \mathrm{~L}^{\mathrm{lo}} \mathrm{CD} 44^{\mathrm{hi}}$ 
T cells compared with WT littermates (Supplemental Figure 2F), but no difference was detected in the percentage of tTregs (Supplemental Figure 2G). Consistent with the increased activation of $\mathrm{T}$ cells in Msn KO mice, splenic-isolated Msn $\mathrm{KO} \mathrm{CD}^{+} \mathrm{T}$ cells produced higher amounts of the proinflammatory cytokines TNF- $\alpha$ (Supplemental Figure 3, A and B) and IFN- $\gamma$ (Supplemental Figure $3, \mathrm{C}$ and D) upon polyclonal stimulation.

The small intestine lamina propria (sLP) and colon lamina propria (cLP) are major sites for generation of pTregs (19); thus we focused our analysis on intestinal pTregs between Msn KO and WT littermate mice. The transcription factor Helios was used to distinguish $\mathrm{FOXP}^{+} \mathrm{Helios}^{\text {lo }}$ pTregs (TGF- $\beta$ signaling is required to generate pTregs) from FOXP ${ }^{+} \mathrm{Helios}^{\text {hi }}$ thymic-derived Tregs (20). We observed a preferential loss in the frequency and number of FOXP $^{+}$Helios $^{\text {lo }}$ Tregs in Msn KO mice in the sLP (Supplemental Figure $3 \mathrm{E}$ ) and cLP (Supplemental Figure 3F), but not FOXP3 ${ }^{+} \mathrm{Helios}^{\text {hi }}$ Treg populations, in comparison with WT littermates. The frequency and number of $\mathrm{FOXP}^{+}{ }^{+}$Helios $^{\text {lo }}$ Tregs were also reduced in the spleen and blood of Msn KO mice (Supplemental Figure 3, G and $\mathrm{H})$. These data suggested that moesin contributes to the generation and homeostasis of $\mathrm{FOXP}^{+}{ }^{+} \mathrm{Helios}^{\mathrm{lo}}$ pTregs. To further isolate the cell-intrinsic effects of moesin on pTregs, we generated mixed bone marrow chimeras (mBMCs) by transferring equal parts of Msn KO (CD45.2) and WT (CD24.1) bone marrow cells into lethally irradiated CD45.1 recipient mice. Eight to ten weeks after reconstitution, mice were euthanized and the frequency of pTregs (FOXP3 ${ }^{+} \mathrm{Helios}^{\mathrm{lo}}$ ) and tTregs (FOXP3 ${ }^{+} \mathrm{Helios}^{\mathrm{hi}}$ ) in the large intestine, spleen, and thymus was assessed. CD45.2 (Msn KO) cells exhibited reduced percentage of FOXP3 ${ }^{+} \mathrm{Helios}^{\text {lo }}$ Tregs compared with CD45.1 (WT) cells (Figure 3, C and D). Consistent with results in straight-knockout mice, we observed an increase in FOXP3 ${ }^{+} \mathrm{Helios}^{\text {hi }}$ Tregs in both the large intestine and spleen (Figure 3, C and D) of the mBMC mice. Further analysis of the thymus showed no significant cell-intrinsic differences between WT and moesin-deficient tTregs (Figure 3E). Together these data support an essential cell-intrinsic function of moesin for $\mathrm{p}$ Treg but not for tTreg generation.

Moesin-deficient primary $C D 4^{+} C D 25^{-} T$ cells are defective in converting to iTregs. Since our study uses total-Msn-KO mice and moesin-deficient $\mathrm{T}$ cells were reported to exhibit defects in egress from the secondary lymphoid organs (7), we used a system where the aforementioned property of moesin should not be a requisite for generation of iTregs. We differentiated splenic $\mathrm{CD} 4^{+} \mathrm{CD} 25^{-} \mathrm{T}$ cells isolated from WT and Msn KO mice with varying doses of TGF- $\beta$ and then assessed FOXP3 expression after 5 days. Compared with FOXP3 expression in WT iTregs, moesin-deficient $\mathrm{CD} 4^{+} \mathrm{CD} 25^{-} \mathrm{T}$ cells were considerably defective at converting to iTregs even at higher doses of TGF- $\beta$ (Figure $4, \mathrm{~A}$ and B). To further examine the cell-intrinsic function of moesin for the generation of pTregs, we purified $\mathrm{CD} 4^{+} \mathrm{CD} 25^{-}{ }^{-} \mathrm{FOXP} 3^{-} \mathrm{T}$ cells from the spleen of 10-weeks-reconstituted 1:1 mBMC mice and adoptively transferred them into $\mathrm{Rag}^{-/-}$mice. Consistent with our earlier observations, $M s n$ KO CD $4^{+} \mathrm{CD} 25^{-}$T cells converted less efficiently to FOXP3 ${ }^{+}$iTregs, even while coexisting with WT CD $4^{+} \mathrm{CD} 25^{-} \mathrm{T}$ cells, which displayed higher FOXP3 expression in the same moesin-sufficient microenvironment (Figure 4C). Together, these data strongly indicate a requirement of moesin for the efficient conversion of $\mathrm{CD} 4^{+} \mathrm{CD} 25^{-} \mathrm{T}$ cells to $\mathrm{FOXP}^{+}$iTregs.
Moesin is important for efficient TGF- $\beta$ signaling. Next, we sought to determine the molecular link between moesin expression and the generation of $\mathrm{FOXP3}^{+}$iTregs. Notably, Msn KO CD4 ${ }^{+} \mathrm{T}$ cells exhibited no defects in their response to TCR ligation (data not shown), evidenced by the intact development of tTregs in these mice. Consistent with our data in Figure 2E, KO CD4 ${ }^{+} \mathrm{T}$ cells proliferated more based on cell number after in vitro culture with anti-CD3e and anti-CD28 antibodies compared with WT CD4 ${ }^{+}$T cells (Supplemental Figure 4A). We then examined the mRNA expression of several transcription factors, including NFAT, c-Rel, STAT5, AP-1, and CREB, reported to assemble directly at the Foxp3 locus during iTreg differentiation (Supplemental Figure 4B and ref. 21). We observed upregulation of Nfatc1, Creb, and Ap-1 mRNAs in moesinoverexpressing iTregs but downregulation in Msn KD iTregs (Supplemental Figure 4, C-G). There were no such changes in C-rel, Sta$t 5 a$, or Stat $5 b$ mRNAs, although Stat $5 b$ mRNA was reduced in $M s n$ KD iTregs (Supplemental Figure 4, H-J). Nevertheless, these data suggested a possible defect upstream of these transcription factors. Moreover, the increased number of Msn KO or KD cells under Treginducing conditions (Supplemental Figure 4A and Figure 2E) is suggestive of diminished responsiveness to TGF- $\beta$ signaling because of its well-known growth inhibition property (11).

To address this possibility, we first used EL4 LAF (EL4) T lymphoma cells, which express FOXP3 upon TCR and TGF- $\beta$ stimulation (22). By intracellular staining, we found that there was a peak increase in SMAD2/3 phosphorylation (pSMAD2/3) at 30 minutes and 1 hour after TGF- $\beta$ stimulation, and this declined after 3-6 hours in scrambled cells (Figure 5, A and B), assessed by flow cytometry. In contrast, pSMAD2/3 was reduced in Msn KD cells (Figure 5, A and B). Similar differences were observed at 24 and 48 hours after stimulation (Figure 5C). Similarly, lower pSMAD2/3 level was detected in Msn KO iTregs compared with WT iTregs after in vitro conversion of primary $\mathrm{CD} 4{ }^{+} \mathrm{CD} 25^{-} \mathrm{T}$ cells isolated from the spleen (Figure 5, D and E). These data strongly indicate that moesin is required for efficient TGF- $\beta$ signaling and that its loss causes reduced responsiveness to TGF- $\beta$ stimulation.

Cell-intrinsic moesin promotes optimal expression and surface abundance of T $\beta R I I$. Since the long-term signaling behavior of the TGF- $\beta$ pathway is determined by receptor dynamics (23), we reasoned that perhaps moesin regulates signaling by directly controlling the TGF- $\beta$ receptors. Moesin indeed fine-tunes the signaling of several cell surface receptors (24). To gain insight into the cause of reduced responsiveness to TGF- $\beta$ in Msn KO cells, we analyzed the surface abundance of T $\beta$ RII on primary $\mathrm{CD} 4^{+}, \mathrm{CD} 8^{+}$, and $\mathrm{B} 22 \mathrm{O}^{+}$lymphocytes from the spleen and MLNs of WT and Msn KO mice. Intriguingly, surface T $\beta$ RII expression on all lymphocytes isolated from Msn $\mathrm{KO}$ mice was reduced in comparison with WT age-matched counterparts (Figure 6, A and B). Similarly, moesin-deficient $\mathrm{CD}^{+}{ }^{+}$and $\mathrm{CD} 8^{+} \mathrm{T}$ cells isolated from the spleen of $\mathrm{mBMC}$ mice reconstituted at 1:1 for 8-10 weeks expressed significantly lower levels of surface T $\beta$ RII (Figure 6C). We next examined T $\beta$ RII levels on iTregs and detected considerably less expression of surface T $\beta$ RII on Msn KO iTregs compared with WT (Figure 6D). Notably, our data have produced consistent conclusions whether using primary T cells or EL4 cells. Indeed, further examination using EL4 cells showed a dramatic reduction of surface T $\beta$ RII on Msn KD EL4 cells compared with scrambled cells by 
A TGF- $\beta(5 \mathrm{ng} / \mathrm{ml})$

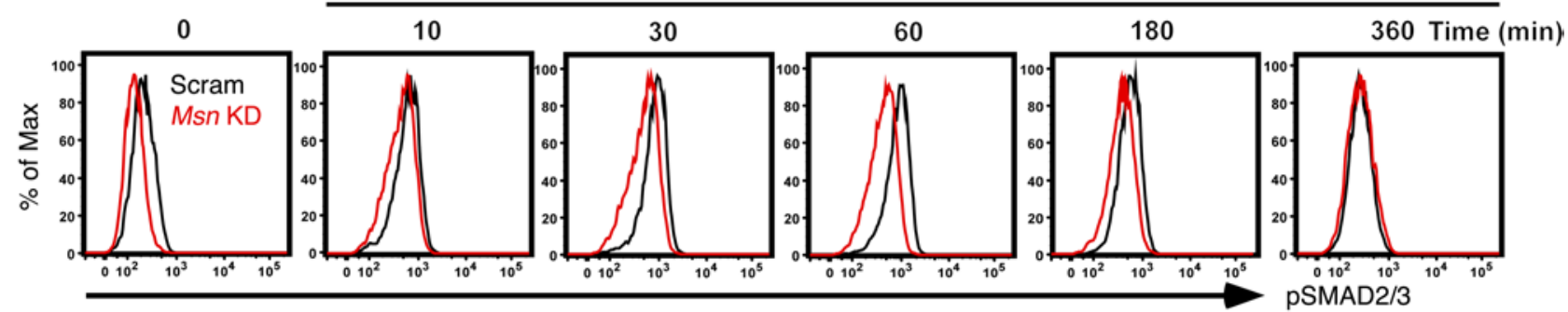

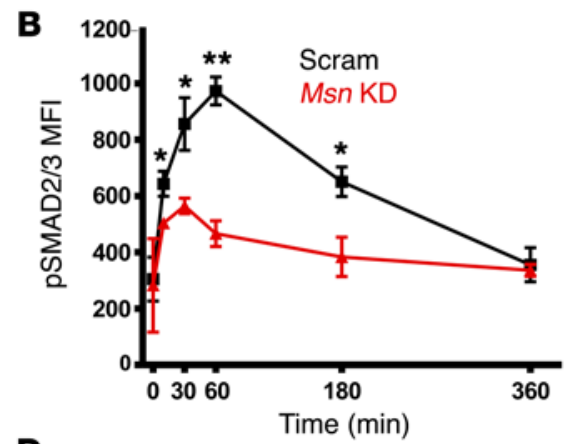

D

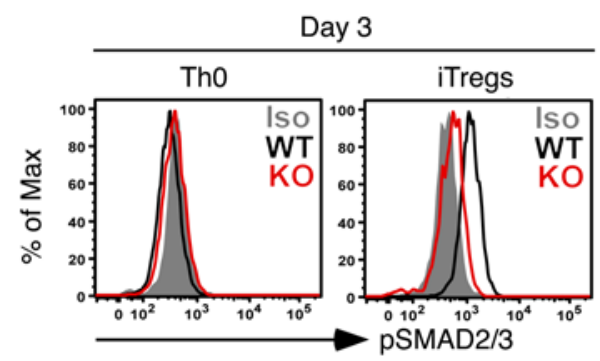

C

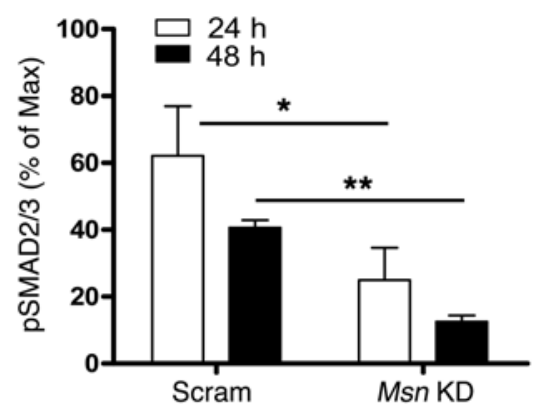

E

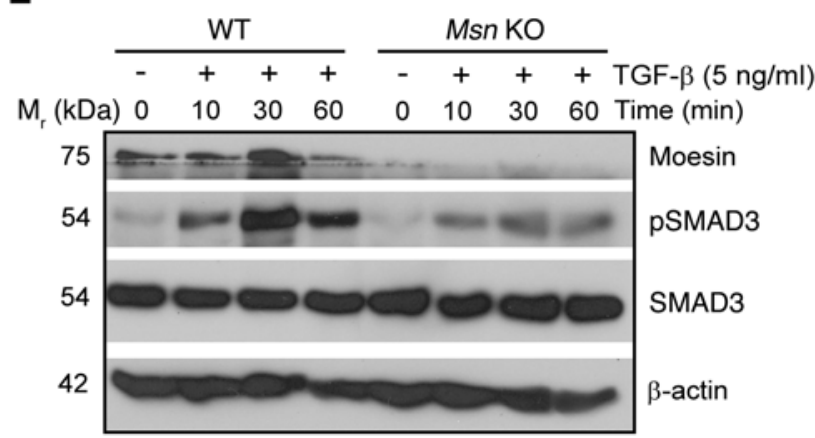

Figure 5. Loss of moesin leads to inefficient TGF- $\beta$ signaling. (A-C) EL4 LAF (EL4) cells transduced with lentiviral scrambled vector (Scram) or Msn shRNA (Msn KD), stimulated with TCF- $\beta$ ( $5 \mathrm{ng} / \mathrm{ml}$ ) and analyzed for intracellular pSMAD2/3 by flow cytometry at the times indicated. MFI, mean fluorescence intensity. ( $\mathbf{D}$ and E) Analyses of phospho-SMAD2/3 (pSMAD2/3) by flow cytometry after 3-day cultures (D) and pSMAD3 and total SMAD3 by immunoblotting (E) stimulated at the indicated times in WT and Msn KO iTregs. Data represent the mean \pm SD of at least 3 independent experiments. ${ }^{*} P<0.05,{ }^{*} P<0.01$ by Student's $t$ test (B and $\left.\mathbf{C}\right)$.

flow cytometry (Figure 6E). Intriguingly, we also detected reduced T $\beta$ RII levels in total cell lysates of Msn KD EL4 cells by immunoblotting with concomitant diminution of pSMAD3 and pAkt2 upon TGF- $\beta$ stimulation (Figure 6F). Analysis of unstimulated cells by confocal microscopy was consistent with the reduced surface distribution of T $\beta$ RII in Msn KD cells. By contrast, scrambled cells displayed T $\beta$ RII mainly on the cell membrane (Figure 6, G and $\mathrm{H}$; red arrowheads indicate T $\beta \mathrm{RII})$. We wondered whether the reduced surface T $\beta R I I$ observed in Msn KO or Msn KD cells was simply due to the lack of trafficking to post-ER compartments. We treated splenic-isolated $\mathrm{CD} 4{ }^{+} \mathrm{CD} 25^{-} \mathrm{T}$ cells either with endoglycosidase $\mathrm{H}$ (Endo $\mathrm{H}$ ) to remove only mannose-rich and hybrid types of N-linked glycosylation or with PNGase to remove almost all $\mathrm{N}$-linked glycosylation. If moesin-deficient cells are defective in post-ER T $\beta$ RII trafficking, then we should detect a stronger lower band in the Endo H condition compared with WT. However, we observed no differences in both Endo H-treated and PNGasetreated conditions, suggestive of intact trafficking in both WT and Msn KO T cells (Figure 6I). Thus, the reduced surface T $\beta$ RII expression in Msn KO cells is not due to ER retention. It is also noteworthy that total T $\beta$ RII level was reduced in the knockout $\mathrm{CD}^{+} \mathrm{T}$ cell lysate, consistent with data using EL4 cells (Figure 6, $\mathrm{F}$ and I). Together, these data suggest an important role for moesin in facilitating efficient TGF- $\beta$ signaling by controlling the surface abundance of T $\beta$ RII.

Moesin interacts with T $\beta R I I$. ERM proteins augment signaling by binding to cell surface receptors via their N-terminal FERM domain, while at the same time interacting with the F-actin via the C-terminus. Our data so far raise an intriguing possibility that moesin enhances TGF- $\beta$ signaling by interacting directly with T $\beta$ RII. To examine this possibility, we performed IP with T $\beta$ RII antibody on untreated EL4 cells, or cells stimulated with TGF- $\beta$ for 1 hour, and then immunoblotted for endogenous moesin. We found that moesin associated with T $\beta$ RII independent of TGF- $\beta$ stimulation (Figure 7A). Moesin also colocalized with T $\beta$ RII by confocal microscopy (Figure 7B). Similarly, transient transfection 
A
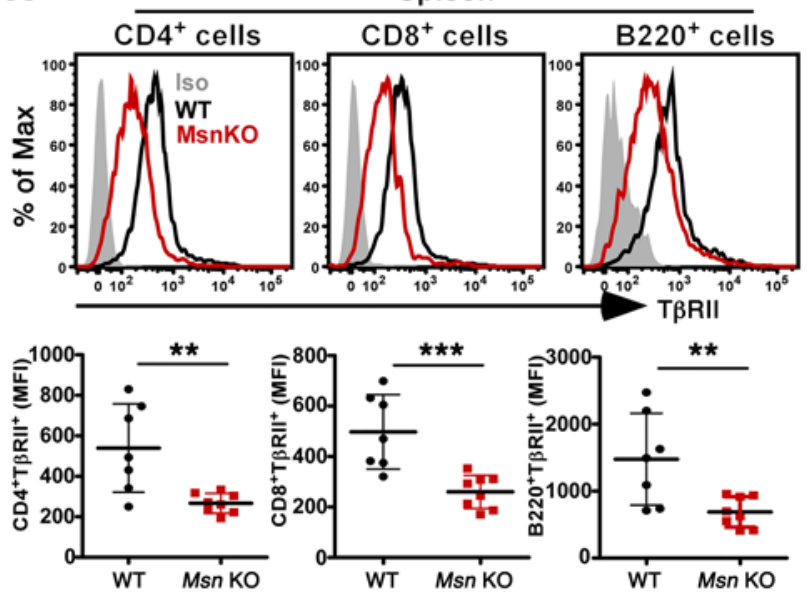

B
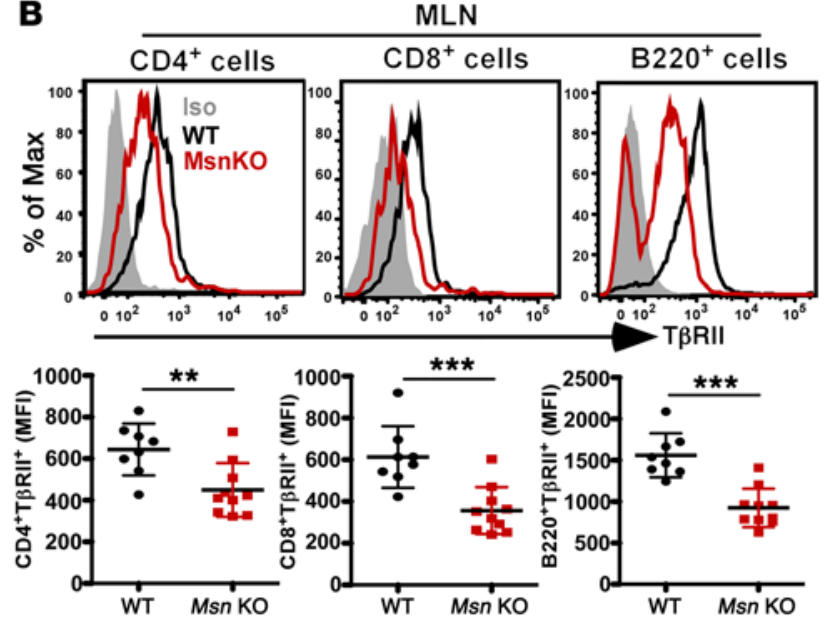

C
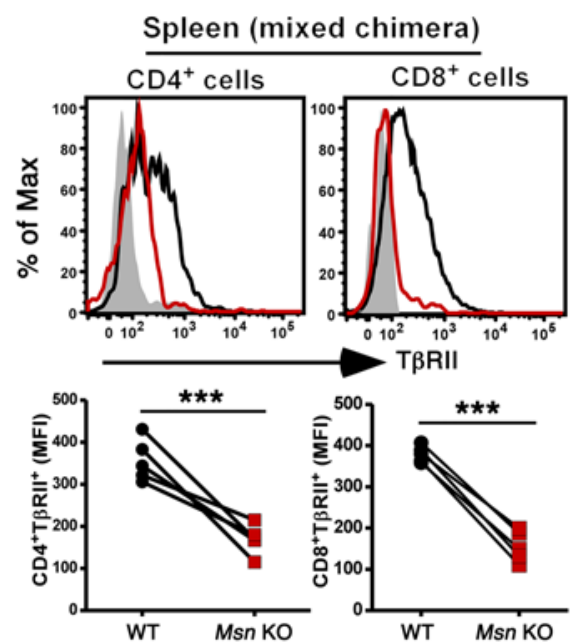

D

iTreg conditions

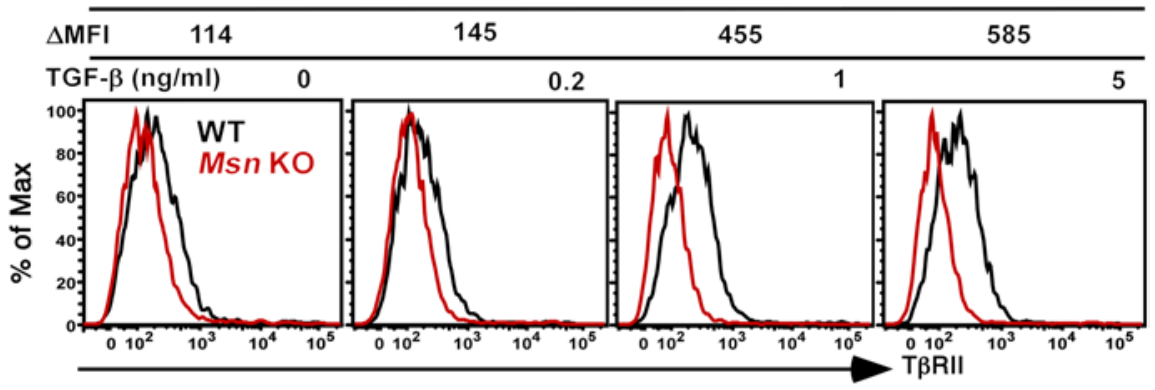

E

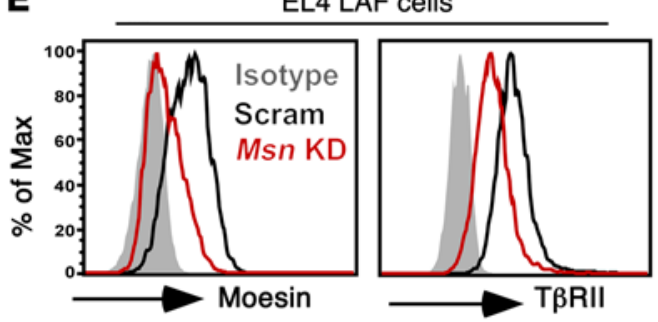

G

EL4 LAF cells
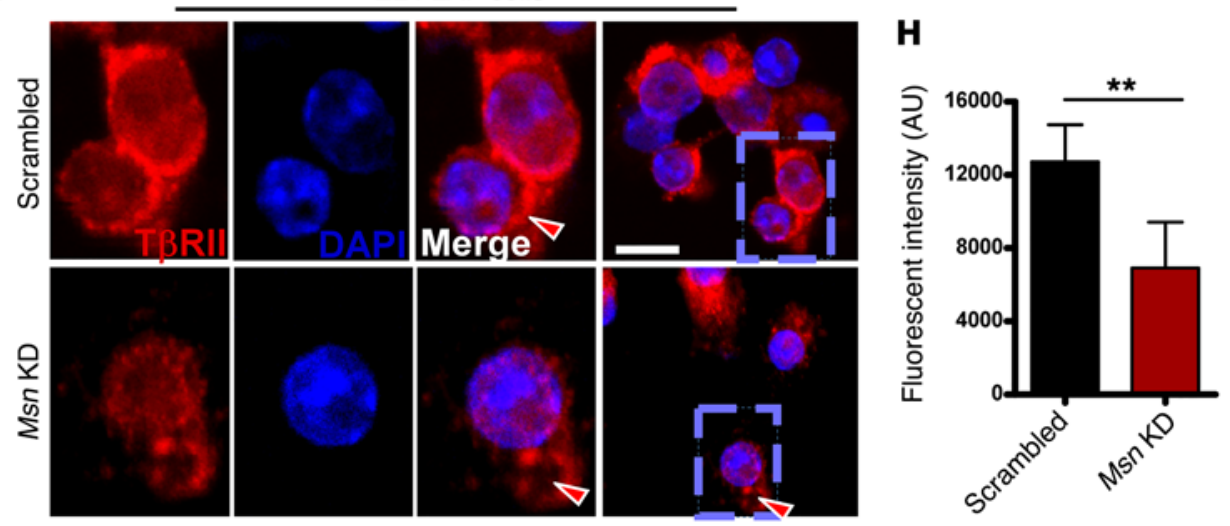

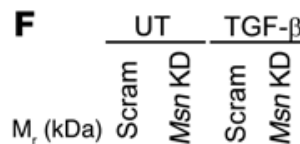
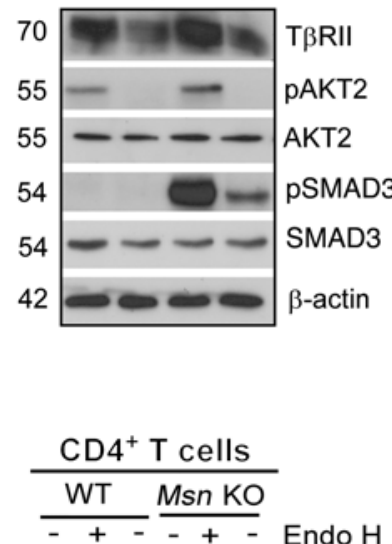

Endo $\mathrm{H}$

$\mathrm{M}_{t}(\mathrm{kDa}) \ldots+\ldots+$ PNGase $\mathrm{F}$

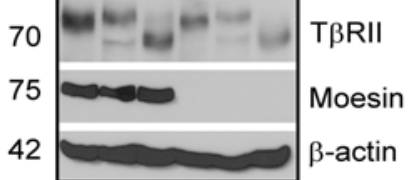


Figure 6. Cell-intrinsic moesin controls efficient surface abundance of T $\beta$ RII. (A and B) Flow cytometry analysis of surface T $\beta$ RII on CD4 ${ }^{+}, \mathrm{CD}^{+}$, and $B 22 \mathrm{O}^{+}$cells from the spleen (A) and mesenteric lymph node (MLN) (B) of 6- to 8-week-old straight-WT and Msn KO littermate mice. (C) Reconstituted 1:1 mix of WT (CD45.1, black) and Msn KO (CD45.2, red) bone marrow chimeric mice were euthanized after 10 weeks, and surface T $\beta R$ II expression on $\mathrm{CD}^{+}, \mathrm{CD}^{+} \mathrm{T}$ cells in the spleen was analyzed. Spleen: WT $n=7$, Msn KO $n=8$; MLN: WT $n=8$, Msn KO $n=10$; mBMCs: $n=5$. (D) Flow cytometry analysis of surface T $\beta R$ II expression on differentiated iTregs from WT and Msn KO mice. $\triangle M F I$ represents differences between WT and Msn KO cells. (E) Flow cytometry of intracellular moesin and surface T $\beta R I I$ levels on scrambled or Msn KD EL4 cells without TGF- $\beta$ stimulation. (F) Immunoblot of T $\beta$ RII, pSMAD3, total SMAD3, phospho-Akt2 (pAkt2), and total Akt2 in EL4 cells untreated (UT) or stimulated for 30 minutes with TGF- $\beta(5 \mathrm{ng} / \mathrm{ml})$. Data are representative of several independent experiments (E and $\mathbf{F}$ ). ( $\mathbf{G}$ and $\mathbf{H}$ ) Confocal microscopy images of unstimulated EL4 thymoma cells fixed/permeabilized and stained intracellularly with anti-T $\beta$ RII antibodies. Data represent at least 3 experiments. Blue dashed lines (right panel) indicate magnified region of interest; red arrowheads indicate surface T $\beta R$ II. Relative fluorescence intensity was calculated using ImageJ software (NIH). Scale bar: $3 \mu \mathrm{m}$. (I) Immunoblot following Endo $\mathrm{H}$ and $\mathrm{PNG}$ ase $\mathrm{F}$ treatment of whole cell lysate of $\mathrm{CD} 4^{+} \mathrm{T}$ cells from WT and Msn KO mice. Data represent the mean \pm SEM $(\mathbf{A}-\mathbf{C})$ or mean \pm SD (H). ${ }^{* *} P<0.01,{ }^{* *} P<0.001$ by Student's $t$ test.

of HEK293FT cells with cyan fluorescent protein-tagged (CFPtagged) moesin (moesin-CFP) and HA-tagged TRRII (TßRII-HA) confirmed interaction between moesin and T $\beta$ RII (Figure 7, C and D). These data suggest that moesin controls TRRII dynamics and TGF- $\beta$ signaling by associating with the receptor.

ERM proteins regulate cell surface proteins by adopting an active/open conformation upon phosphorylation. To address the role of phosphorylated moesin in associating with TßRII, we generated phosphomimetic moesin mutants. Phosphorylation of moesin at the threonine 558 residue induces conformational changes leading to its activation (25). We cotransfected HEK293FT cells for 36 hours with WT moesin-CFP (moesin-WT-CFP, or WT), constitutively active/open moesin (moesin-T558D-CFP, or TD), or inactive/closed moesin (moesin-T558A-CFP, or TA) mutants, together with a TBRII-HA plasmid. Transfected cells were then stimulated with or without TGF- $\beta(5 \mathrm{ng} / \mathrm{ml})$ at $37^{\circ} \mathrm{C}$ for 1 hour. Lysates were prepared and co-IP was performed using anti-GFP and anti-HA antibodies. We found that TBRII interacts with WT moesin as well as the 2 moesin mutants (TD and TA). Co-IP with the TD mutant (active) showed a stronger interaction with TRRII than that with the TA mutant (Figure 7, E-G). There is a precedent for ligand-independent binding between moesin and receptors on the plasma membrane (26).

Moesin stabilizes surface expression of T $\beta R I I$. Next, we determined the significance of moesin-T $\beta$ RII interaction by asking whether moesin helps stabilize surface T $\beta$ RII expression. We first determined the half-life of cell surface T $\beta$ RII with and without moesin after cyclohexamide treatment for up to 6 hours using EL4 cells. The half-life of cell surface T $\beta R I I$ on Msn KD and scrambled cells was approximately 3 and 6 hours, respectively. In contrast, the half-life of MHC class I (MHCI) molecules was similar between scrambled and Msn KD cells (Supplemental Figure 5). Consistently, the half-life of T $\beta R I I$ in primary splenic $\mathrm{CD} 4^{+}$and $\mathrm{B}_{22 \mathrm{O}^{+}}$cells was significantly lower in Msn KO cells compared with their WT counterparts (Figure 8, A and B). To determine whether moesin is important for stabilizing presynthesized surface T $\beta$ RII, we treated cells with brefeldin A (BFA) to block newly synthesized protein transport to post-ER compartments. $\mathrm{CD} 4^{+} \mathrm{T}$ cells were treated with BFA for 2 and 5 hours, and then washed. As expected, surface T $\beta$ RII and MHCI expression on WT CD $4^{+} \mathrm{T}$ cells declined upon BFA treatment and recovered when BFA was removed. Moesin-deficient $\mathrm{CD}^{+} \mathrm{T}$ cells displayed a similar pattern, but exhibited more dramatic loss and slower recovery of T $\beta R I I$ expression than WT lymphocytes (Figure 8C, left). In comparison, the disappearance and reappearance of surface MHCI molecules followed a similar kinetics between WT and moesin-null $\mathrm{CD} 4^{+} \mathrm{T}$ cells (Figure $8 \mathrm{C}$, right). Consistently, moesin deficiency in $\mathrm{CD} 4^{+} \mathrm{T}$ cells isolated from the spleen of 1:1 mBMC mice at 10 weeks resulted in delayed recovery of surface TRRII expression after washing out of BFA (Figure 8D). Together, our data strongly indicate that moesin interacts with TRRII and this interaction is involved in intrinsically regulating the stability and surface abundance of T $\beta R I I$ to promote efficient TGF- $\beta$ signaling.

Loss of moesin confers reduced Treg suppressive capacity. Knowing that moesin is required for optimal generation of TGF- $\beta-$ induced Tregs, but dispensable for tTreg development, we next sought to investigate the function of Tregs in Msn KO mice. We used the $\mathrm{T}$ cell transfer-induced colitis model to address this question $(19,27)$. Briefly, FACS-sorted WT CD $4^{+} C D 25^{-} C D 45 R^{\text {hi }}$ $\mathrm{T}$ cells $\left(5 \times 10^{5}\right.$ per mouse) from the spleen of 5 - to 6-week-old mice were adoptively transferred either alone (effector $\mathrm{T}$ cells, Teff) or together with WT Tregs or Msn KO CD $4^{+} \mathrm{CD} 25^{+}$Tregs (1 $\times 10^{5}$ per mouse) into Rag2 $\%$ mice ( $n=4$ Teff and $n=5 \mathrm{WT} / M s n$ $\mathrm{KO})$ at a 5:1 ratio. WT $\mathrm{CD} 4^{+} \mathrm{CD} 25^{+}$Tregs efficiently suppressed development of intestinal inflammatory bowel disease (IBD) as measured by body weight changes. Although modest, Msn KO $\mathrm{CD} 4{ }^{+} \mathrm{CD} 25^{+}$Tregs were less efficient in protecting mice against development of colitis (Supplemental Figure 6, A-C) and $\mathrm{T}$ cell activation (Supplemental Figure 6D). Intriguingly, we also observed a reduced population of the FOXP3 ${ }^{+} \mathrm{Helios}^{\text {lo }}$ pTregs in the spleen and MLNs of IBD mice, but not the FOXP3 ${ }^{+} \mathrm{Helios}^{\mathrm{hi}}$ tTregs in this model (Supplemental Figure 6E). These data hinted that although moesin is dispensable for tTreg generation, it contributes to their optimal suppressive function. To further assess the function of Tregs in Msn KO mice, we next purified $\mathrm{CD}^{+}{ }^{+} \mathrm{CD} 25^{+}$Tregs from the spleen of WT and Msn KO littermates, cocultured them with CFSE-labeled effector T cells and $\gamma$-irradiated splenocytes for 3 days, and examined their suppressive activity in vitro. Cells were analyzed by flow cytometry after 3 days for CFSE dilution at various ratios of Tregs and effector $\mathrm{T}$ cells. Whereas WT Tregs suppressed proliferation of effector T cells, Msn KO Tregs did so less efficiently (Supplemental Figure 7, A and B). Further analysis of Tregs showed reduced expression of key Treg suppressive molecules, including CTLA4, CD39, and PD-1, in moesin-deficient mice compared with WT. However, no differences were observed in GARP, GITR, or NRP1 expression between WT and Msn KO Tregs (Supplemental Figure 7C). Thus, consistent with our IBD data, the suppressive capacity of Tregs is defective in Msn KO mice. These data suggest a requirement of moesin for optimal Treg suppression and are also consistent with the requirement of moesin for the efficient generation of induced Tregs. 
A

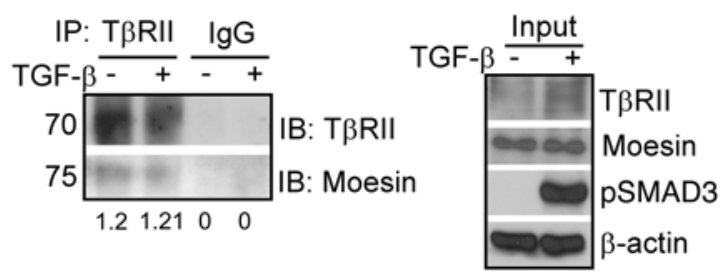

B
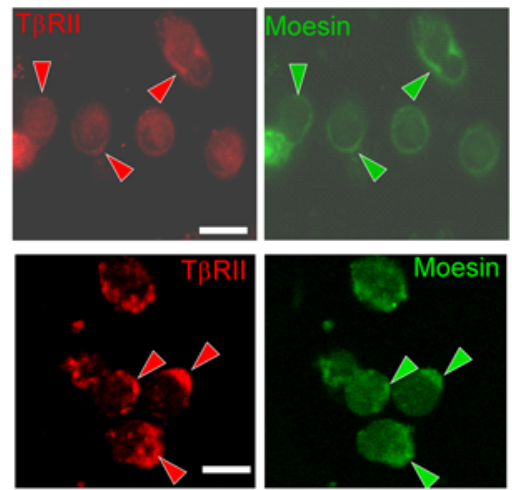

D IP: HA/GFP IgG

Moesin-CFP ++++

T $\beta \mathrm{RII}-\mathrm{HA}++++$

TGF- $\beta-++$

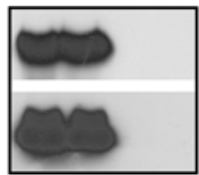

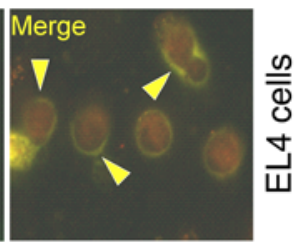

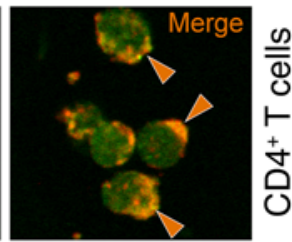

E

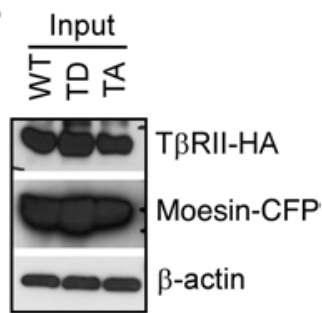

IB: anti-T $\beta R$

(T $\beta$ RII-HA)

IP: anti-HA/lgG

IB: anti-GFP

IP: anti-GFP/lgG

$48 \quad 50 \quad 0 \quad 0$

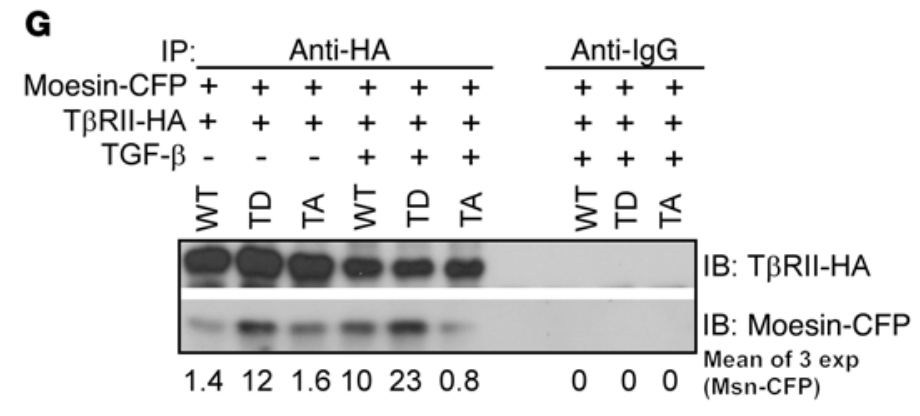

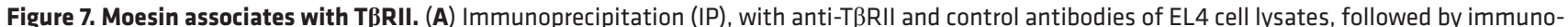
blotting. Mean band intensity of moesin is below. (B) Confocal microscopy images of EL4 cells and CD4 ${ }^{+}$T cells stimulated with TCF- $\beta$ and stained with

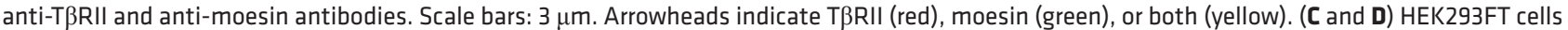
cotransfected with plasmids encoding WT moesin tagged with CFP at the carboxy terminus (moesin-CFP) and T $\beta R$ II tagged with HA at the carboxy terminus (T $\beta R$ II-HA) and IP with anti-GFP and anti-HA antibodies. Input: whole cell lysate immunoblotting (throughout). (E-G) IP and immunoblot (as in C) of HEK293FT cells cotransfected with CFP-tagged WT or phosphomimetic moesin mutants and T $\beta R$ II-HA constructs. Data are representative of at least 3 (A-C) or 4 (D-C) independent experiments. Mean band intensity of T $\beta$ RII-HA (C and F) and Msn-CFP (C) based on ratio of CFP and HA.

Loss of moesin augments adoptive $T$ cell therapy of B16 melano$m a$. This study has revealed that moesin promotes a cell-intrinsic optimal TGF- $\beta$ signaling, which is also important for efficient generation of TGF- $\beta$-induced Tregs. We have also observed that though the development of tTregs in Msn KO mice is unabated, their optimal suppressive capacity is impaired. Thus, based on documented functions of Tregs in cancer, including limiting effective antitumor immune responses to promote tumor progression (28), we wondered whether the breakdown in optimal Treg function and the cell-intrinsic loss of efficient TGF- $\beta$ signaling in Msn KO mice would support a potent antitumor immune response against B16 melanoma after adoptive $\mathrm{T}$ cell transfer. To this end, WT and Msn KO mice were injected s.c. with B16-F1 melanoma tumor cells (Figure 9A). After palpable tumors were established, irradiated mice were infused with fully activated $\mathrm{CD}^{+} \mathrm{T}$ cells (Tc1) from Pmel-1 TCR transgenic (Pmel-1) mice, which recognize an endogenous B16 tumor antigen $\left(\mathrm{H}-2 \mathrm{D}^{\mathrm{b}}\right.$-restricted gp10025-33 peptide) (29). We found that adoptive $\mathrm{T}$ cell therapy in the WT mice slowed tumor growth, but $100 \%$ of the WT mice relapsed and succumbed to the progressive diseases (Figure 9B). By comparison, a majority of $\mathrm{Msn}$ KO mice were cured of melanoma. The delay in tumor recurrence observed in Msn KO cells correlated with enhanced persistence of donor Tc1 cells in recipient mice (Figure 9C) and increased survival (Figure 9D).

Next, we reasoned that in a TGF- $\beta$-rich environment such as the tumor microenvironment (TME), moesin is important for augmenting optimal TGF- $\beta$ signaling to allow efficient conversion of naive $\mathrm{CD} 4^{+} \mathrm{T}$ cells into Tregs. These Tregs then promote tumor immune-escape and progression by suppressing antitu- 
A

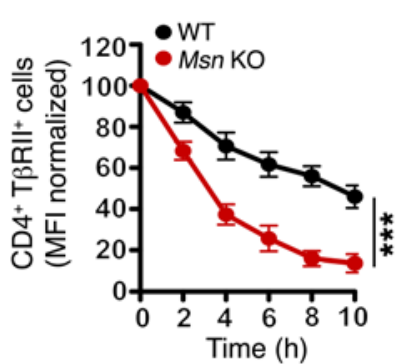

$\mathrm{CD}^{+} \mathrm{T}$ cells - Cyclohexamide

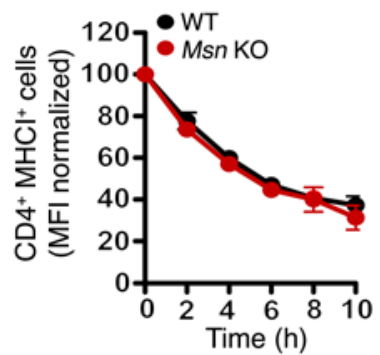

$\mathrm{CD} 4^{+} \mathrm{T}$ cells $-\mathrm{BFA}$

C

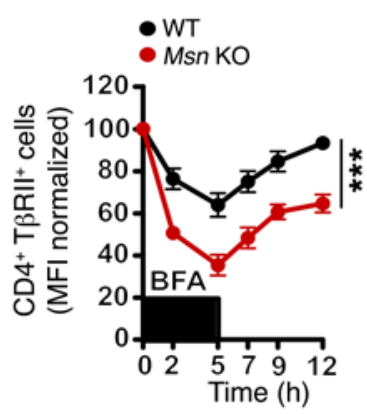

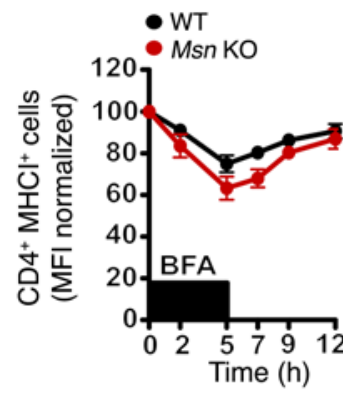

B

B220+ B cells - Cyclohexamide
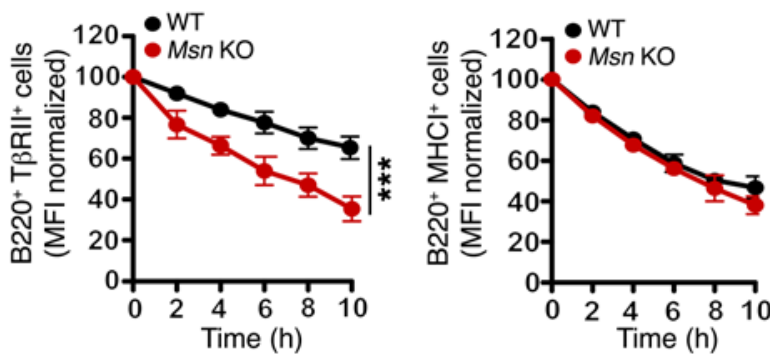

D

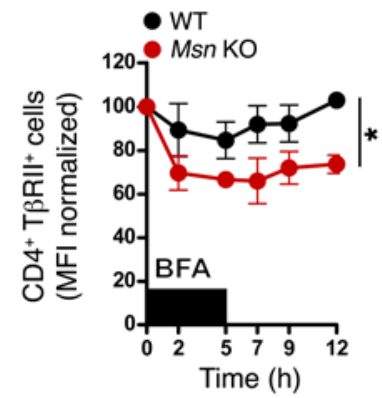

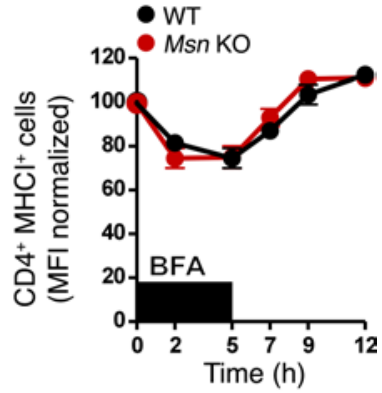

Figure 8. Moesin stabilizes surface abundance of T $\beta R$ III. (A and B) Primary CD4+ $T$ cells (A) and B220+ $B$ cells (B) from the spleen of WT and Msn KO mice were treated with cyclohexamide at the indicated times and surface T $\beta$ RII analyzed by flow cytometry. (C) Flow cytometry analysis of primary CD4 ${ }^{+} T$ cells isolated from the spleen of WT and Msn KO mice, and treated with brefeldin A (BFA), $20 \mu \mathrm{g} / \mathrm{ml}$, for up to 5 hours and then washed. Cell surface T $\beta R$ II was left to recover for up to 12 hours prior to analysis. (D) Reconstituted 1:1 mix of WT (CD45.1, black) and Msn KO (CD45.2, red) bone marrow chimeric mice treated as in C. Data represent the mean \pm SD of 3 independent experiments in triplicate. ${ }^{*} P<0.05,{ }^{* *} P<0.001$ by 2 -way ANOVA.

mor immune responses. To test, we injected B16-F1 cells s.c. into B6.Rag2 $2^{--}$mice. Palpable tumors were allowed to establish, and irradiated mice were coinfused with fully activated $\mathrm{CD} 8^{+}$ $\mathrm{T}$ cells from Pmel-1 mice together with splenic-purified CD45.1 (WT>WT) or CD45.2 (Msn KO>WT) $\mathrm{CD} 4{ }^{+} \mathrm{CD} 25^{-} \mathrm{T}$ cells isolated from bone marrow chimera mice (Figure 9E). In agreement with our hypothesis, we found that mice infused with Msn KO T cells harbored smaller tumors weighing less compared with mice receiving WT CD4 ${ }^{+}$T cells (Figure 9, F and G). The reduced tumor growth in $M s n$ KO-infused mice correlated with better $\mathrm{CD}^{+}$ $\mathrm{T}$ cell engraftment and persistence in the TME (Figure 9H). More importantly, we detected impaired conversion to FOXP3 ${ }^{+}$iTregs in the TME of mice infused with Msn $\mathrm{KO} \mathrm{CD} 4^{+} \mathrm{CD} 25^{-} \mathrm{T}$ cells (Figure 9I), which also had lower surface T $\beta$ RII expression (Figure 9J). Interestingly, a similar observation was also detected in the spleen of tumor-bearing mice (Figure 9, K and L).

Altogether, we have uncovered a previously unknown function for moesin in promoting optimal TGF- $\beta$ signaling via direct control of T $\beta$ RII. In the absence of TGF- $\beta$, moesin and T $\beta$ RII may still associate together. However, in the presence of ligand, moesin associates more with T $\beta$ RII and triggers its internalization, possibly via clathrin-endocytic vesicles (30) to promote a more potent TGF- $\beta$ signaling. Moesin is also involved in maintaining the abundance of T $\beta$ RII on the cell surface. In $\mathrm{T}$ cells moesin promotes efficient TGF- $\beta$ signaling, which leads to the assembling of transcription factors on the Foxp3 locus and consequent expression of FOXP3 to promote efficient generation of $\mathrm{FOXP}^{+}$iTregs that constrains effector $\mathrm{T}$ cell functions (Figure 10).

\section{Discussion}

Post-transcriptional regulation of TGF- $\beta$ downstream target genes has only recently emerged as an important mechanism for TGF- $\beta$ action. Before the current work, it was unclear whether translational repression by hnRNP E1 is operational in CD4 ${ }^{+}$ $\mathrm{T}$ cells; neither was it known what genes are being repressed, nor the contribution of this mechanism to the fundamental $\mathrm{T}$ cell biology. In addition, ERM proteins have been mainly reported to control cell motility, as well as the regulation of cell-cell adhesion $(1,31)$. However, the role of ERM proteins in regulating signal transduction pathways is less understood, and whether they control the TGF- $\beta$ receptors is unknown. In this study, we began to examine these questions and have made several novel observations, which provide significant advancement to our understanding about the role of the ERM proteins in controlling various signal transduction pathways: (a) We discovered that many TGF- $\beta$ target genes involved in EMT, including moesin, are also regulated in $\mathrm{CD}^{+} \mathrm{T}$ cells in the same hnRNP E1-dependent fashion as in epithelial cells. (b) Induced by TGF- $\beta$, moesin in turn forms a forward-feed loop by facilitating a cell-intrinsic optimal SMAD signaling. (c) Moesin exerts its TGF- $\beta$-enhancing activity by binding to and stabilizing T $\beta$ RII. (d) Moesin is involved in the efficient generation of FOXP3 ${ }^{+}$iTregs both in vitro and in vivo. (e) Moesin is required for the optimal function of Tregs.

ERM proteins are known to tune the signaling of several cell surface receptors, including CD43, CD44, CD146, CD93, L-selectin, ICAM1-3, and S1PR1 $(1,24,32)$. Notably, the main function of moesin in lymphocytes is the control of activation 
A

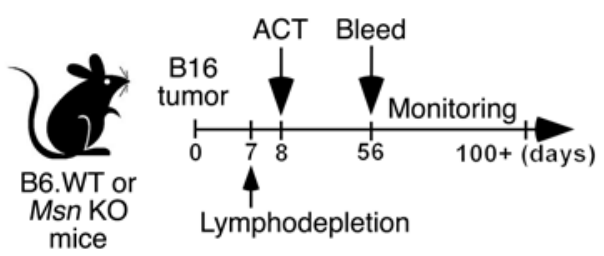

E
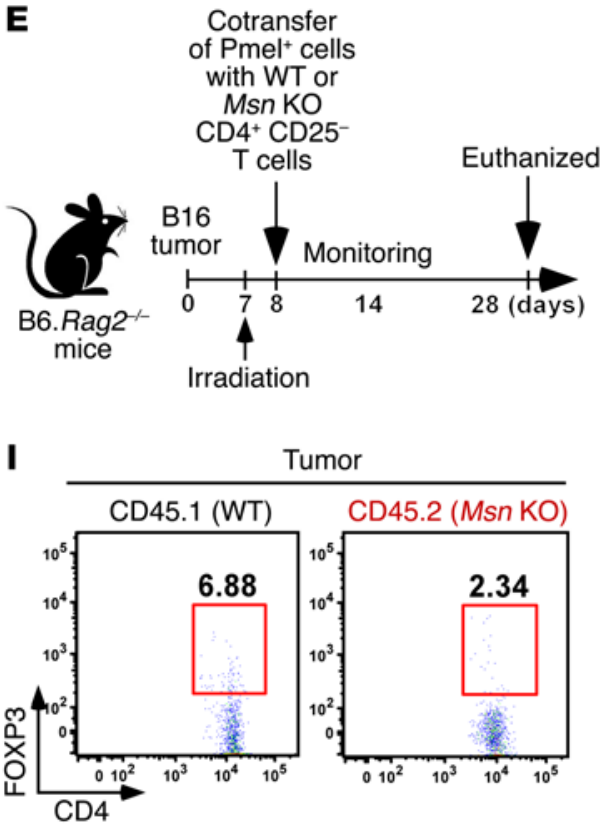

K

Spleen

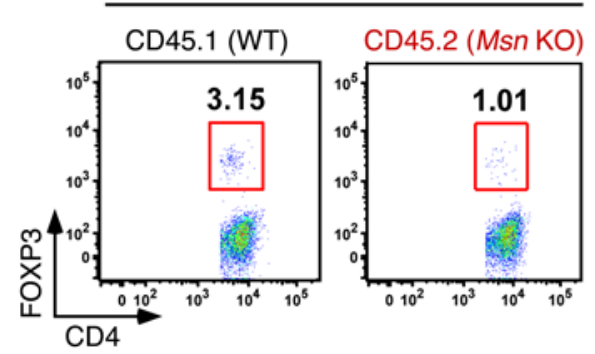

B

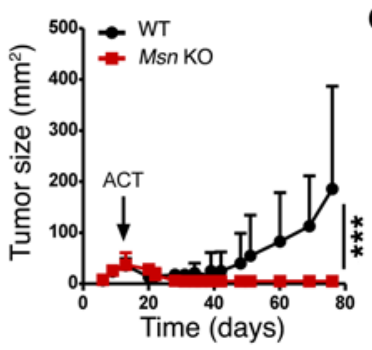

$\mathbf{F}$

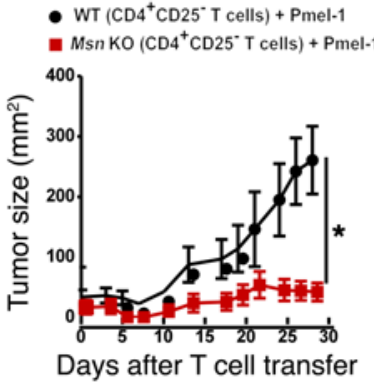

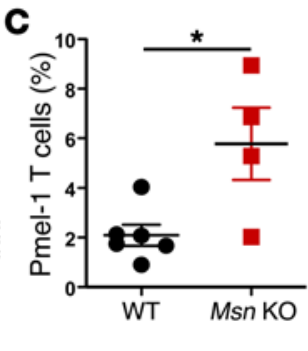

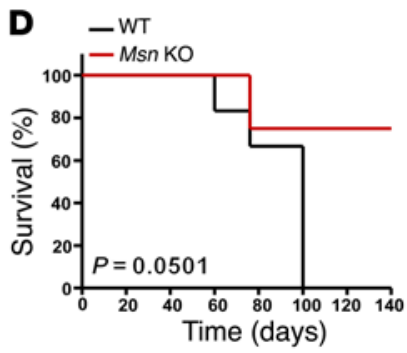

G
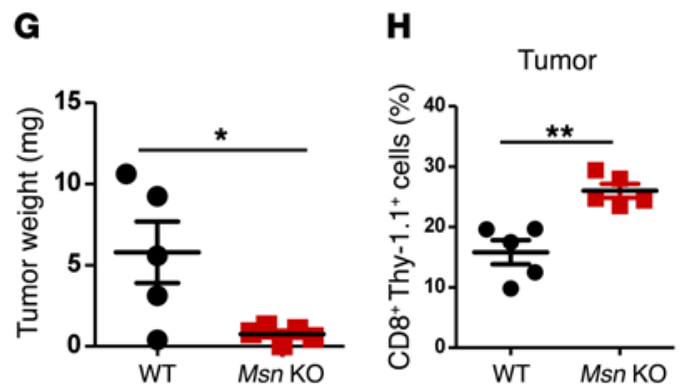

Figure 9. Moesin loss potentiates adoptive T cell therapy of melanoma. (A) Treatment scheme for B6 mice injected s.c. with B16-F1 melanoma tumor cells $\left(2.5 \times 10^{5}\right) 7$ days before lymphodepletion with 6 Gy total-body irradiation and adoptive cell transfer (ACT) of $2 \times 10^{6}$ Pmel-1 T cells (i.v.) at day 8 . (B) Tumor growth kinetics in individual mice treated as indicated in A; WT, $n=6 ;$ Msn KO, $n=4$. (C) Frequency of donor Pmel-1 CD8 ${ }^{+}$T cells in the blood of WT and Msn KO mice from B at 8 weeks. (D) Survival analysis of WT and Msn KO mice upon tumor injection and adoptive T cell transfer. (E) B6.Rag2 ${ }^{-/-}$mice treated as in $\mathbf{A}$ and ACT (i.v.) on day 8 with $2 \times 10^{6}$ Pmel-1 T cells coinfused with CD4+CD25- T cells isolated from WT (CD45.1, black) or Msn KO (CD45.2, red) bone marrow chimeric mice. WT CD45.1 are from WT>WT bone marrow chimeric mice and CD45.2 are from Msn K0>WT chimeric mice reconstituted for 8 weeks. (F) Tumor growth kinetics in mice treated as indicated in E. (G and $\mathbf{H})$ Tumor weight and percentage of tumor-infiltrating Pmel-1 CD8 ${ }^{+} \mathrm{T}$ cells at endpoint. (I and J) Endpoint analysis of the tumor-infiltrating lymphocytes (TILs) for FOXP3 ${ }^{+}$iTregs in the tumor (I) and expression of TRRII on CD4 ${ }^{+}$TILs (J). (K and $\mathbf{L}$ ) The spleen of tumor-bearing mice analyzed for FOXP3 ${ }^{+}$iTregs $(\mathbf{K})$ and T $\beta R I I$ expression on splenic CD4+ ${ }^{+}$cells $(\mathbf{L})$. $n=5$ per group. Data are reported as the mean \pm SEM. ${ }^{*} P<0.05,{ }^{* *} P=0.01,{ }^{* *} P=0.001$ by Student's $t$ test (C and $\left.\mathbf{G}-\mathbf{L}\right)$, by Mann-Whitney test (B and $\left.\mathbf{F}\right)$, or by log-rank test (D).

and migration, a property it shares with ezrin $(7,33)$. Whether ERM proteins play any role during the differentiation of naive $\mathrm{CD}^{+} \mathrm{T}$ cells to iTregs is completely unknown. For the first time to our knowledge, we found that moesin regulates a cellintrinsic node that promotes the generation of TGF- $\beta$-induced Tregs. Indeed, mice lacking moesin have fewer FOXP3 ${ }^{+} \mathrm{Helios}^{\mathrm{lo}}$ pTregs in the spleen and large intestine; however, $\mathrm{FOXP}^{+}$
Tregs in the thymus were comparable between $M s n$ KO and WT mice. Adoptive transfer of purified splenic CD $4^{+} \mathrm{CD} 25^{-} \mathrm{FOXP}^{-}$ $\mathrm{T}$ cells from 10-weeks-reconstituted 1:1 mBMC mice into $\operatorname{Rag}^{-/-}$mice further demonstrated an inefficiency of Msn KO naive $\mathrm{CD}^{+}{ }^{+} \mathrm{T}$ cells to convert to $\mathrm{FOXP}^{+}$-induced Tregs. Therefore, moesin favors generation of induced pTregs, but is dispensable for tTreg development. 


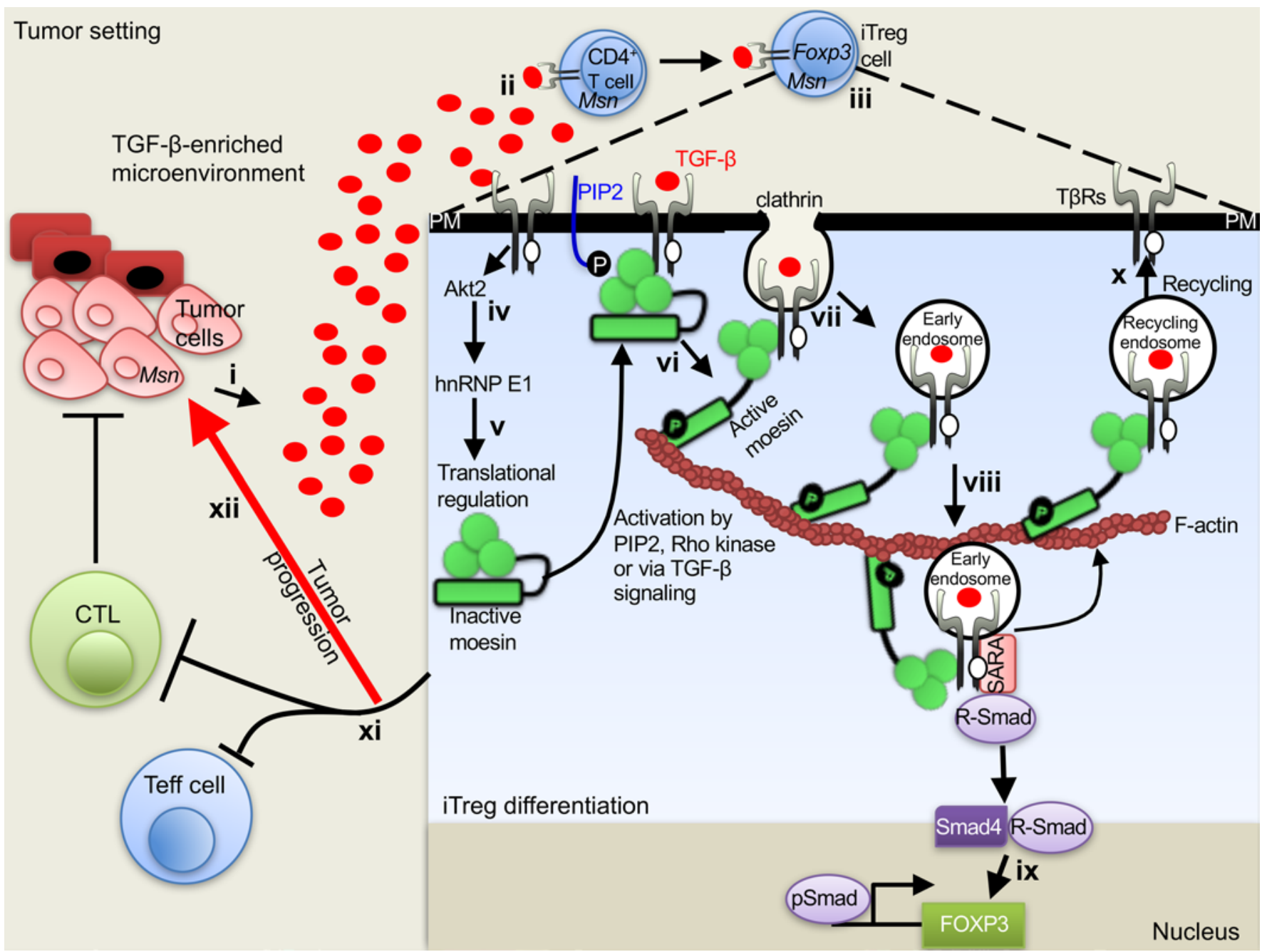

Figure 10. Schematic model on the roles of moesin in controlling optimal TGF- $\beta$ signaling and promoting iTreg generation. (i-iii) Under pathological conditions such as cancer, TCF- $\beta$ production by tumor cells binds to cognate receptors on T cell surfaces and triggers signaling events that lead to FOXP3 expression and induced Treg development. (iv-vi) Signaling via the TCF- $\beta$ noncanonical Akt/hnRNP E1 axis leads to post-transcriptional moesin expression. The TGF- $\beta$, Rho kinase, and/or phosphatidylinositol 4,5-bisphosphate[Ptdlns $(4,5) P 2$ ] signaling pathways lead to phosphorylation/activation of moesin and aid moesin binding to F-actin. (vii-ix) Moesin-F-actin binding may promote internalization of TGF- $\beta$ receptors possibly via early endosomes, which feeds forward to promote optimal TGF- $\beta$ signaling leading to efficient FOXP3 induction and iTreg differentiation. ( $x$ ) Moesin may also promote efficient recycling of TCF- $\beta$ receptors to maintain the abundance of T $\beta$ RII on the cell surface. (xi and xii) Differentiated induced Tregs then suppress the proliferation of other immune cells such as cytotoxic T lymphocytes (CTLs) and effector T (Teff) cells to limit antitumor responses and promote tumor progression. PM, plasma membrane.

To understand this difference in moesin requirement, we initially assessed TCR expression between WT and Msn KO T cells. When cultured together, we found that Msn KO T cells proliferated more (Supplemental Figure 4A), suggestive of a functional TCR and signaling. Indeed, splenic $\mathrm{CD}^{+} \mathrm{T}$ cells are increased in $M s n$ KO mice and produce an increased amount of proinflammatory TNF- $\alpha$ and IFN- $\gamma$ cytokines (Supplemental Figure 3, A-D). The presence of ezrin may also support an intact TCR function, since ezrin functions together with moesin to control T cell activation. This argument is further supported by the dispensable role of moesin in tTreg development, which cannot be selected in the thymus without an appropriate TCR. Thus, a defective TCR cannot explain the difference in moesin requirement by pTregs and tTregs. Instead, we found that moesin is important for optimal
TGF- $\beta$ signaling. Indeed, the dynamics of SMAD2/3 phosphorylation were impaired in moesin-deficient cells, and iTregs displayed reduced SMAD2/3 phosphorylation, which correlated with considerably less FOXP3 expression (Figures 4 And 5). Notably, iTreg differentiation - in vitro or in vivo - is absolutely dependent on an appropriate TGF- $\beta$ signaling. In contrast, tTregs can still develop in the absence of an intact TGF- $\beta$ signaling.

In support that moesin controls efficient TGF- $\beta$ signaling, we detected significantly reduced levels of T $\beta$ RII on $\mathrm{CD} 4^{+}, \mathrm{CD} 8^{+}$, and $\mathrm{B} 22 \mathrm{O}^{+}$lymphocytes as well as on iTregs from moesin-deficient mice. In addition, adoptive transfer of Tregs in a colitis model further supported a role for moesin in optimal Treg function. Though the diminished suppressive activity of Msn KO Tregs was modest, the normally superior Treg suppressive capacity (seen with WT 
Tregs) was not observed with Msn KO Tregs $(34,35)$. Further analysis revealed reduced expression of key Treg suppressive factors. In another study, moesin-deficient mice were protected against recurrence of B16 melanoma tumors after adoptive $\mathrm{T}$ cell transfer. Moreover, moesin-deficient naive $\mathrm{CD} 4^{+} \mathrm{T}$ cells did not convert to Tregs in the TME and instead potentiated antitumor immune responses against B16 melanoma tumor.

These data suggest that identification of moesin inhibitors would serve as a good combinatorial strategy for adoptive $\mathrm{T}$ cell therapy and immunotherapy for the treatment of cancer. The conclusive link between moesin and TGF- $\beta$ signaling comes from the genetic study using mBMC mice, when deletion of Msn led to a considerable reduction in responsiveness to TGF- $\beta$ stimulation, caused in part by a substantial reduction in the surface abundance of T $\beta$ RII on lymphocytes. These data support a cell-intrinsic role for moesin in promoting TGF- $\beta$ signaling and optimal iTreg generation. The marked reduction in TGF- $\beta$ signaling and fewer $\mathrm{FOXP}^{+}$iTregs in the moesin KO mice supported the rapid expansion and persistence of antigen-specific Pmel- $1 \mathrm{CD} 8^{+} \mathrm{T}$ cells. This is consistent with a previous report, which suggested that aborted TGF- $\beta$ programming in T cells confers protection against B16 melanoma and EL4 thymoma cells (36). Indeed, lower numbers of Tregs in cancer patients have been observed to correlate with better responses to chemotherapy (37), and multiple experiments suggest that therapeutically targeting Tregs promotes antitumor immunity and tumor rejection in mouse models of cancer (38). Moreover, analyses of moesin levels in tumors also correlate with poor prognosis of many cancers (39-41).

After TGF- $\beta$ stimulation, TGF- $\beta$ receptors have been shown to internalize via clathrin and early endosomes to promote potent TGF- $\beta$ signaling (42). The receptors are also recycled to the cell surface via recycling endosomes where Rab11 plays a key role (23). However, the factors that promote TGF- $\beta$ receptor internalization and recycling are less clear. Our data strongly suggest that moesin controls the internalization (data not shown) and stabilization of cell surface T $\beta$ RII. Indeed, moesin was reported to interact with Rab11 and rescues defects associated with Rab11 deficiency, which may be a mechanism by which moesin could promote recycling of the TGF- $\beta$ receptors (43). Our study focused on T $\beta$ RII since TGF- $\beta$ signaling can occur via T $\beta$ RII independently of T $\beta R I$ activation (44). Studies with cyclohexamide or BFA confirmed disruption in the stability of surface T $\beta R I I$ in moesin-deficient cells. Importantly, we demonstrated that moesin interacts efficiently with T $\beta$ RII and that this interaction was enhanced in cells transfected with a constitutively active moesin mutant. Moesin also regulates clathrin internalization of cell surface receptors by binding to clathrin-coated endocytic vesicles (30). Interestingly, we also observed interactions between moesin and T $\beta$ RII in cells transfected with an inactive/closed moesin mutant. This implies that inactive moesin still binds to T $\beta$ RII; however, activation is required for $\mathrm{F}$-actin binding in order to promote internalization of moesin-regulated surface receptors for potent signaling. Accordingly, inactive ezrin mutant also associates with the cell membrane, and inactive ERM proteins can still localize to the plasma membrane (26). Our novel findings can explain some of the existing literature on the roles of moesin in other settings. For example, fibrosis of the kidney and liver due to collagen secretion, a
TGF- $\beta$-dependent process, was attenuated after siRNA silencing or deletion of Msn in mice (45). The reduced kidney fibrosis was consistent with impaired TGF- $\beta$ signaling (46).

Our overall discovery suggests that this mechanism is not limited to the Treg lineage, as moesin was also regulated differently in Th17 cells (Figure 1, A-D). Thus, while we acknowledge that moesin has a much broader function than controlling iTregs, our in vitro and in vivo data have conclusively uncovered that there is a requirement of moesin for efficient iTreg generation and optimal tTreg suppression. A key defect in moesin $\mathrm{KO}$ mice is a reduced responsiveness to TGF- $\beta$ signaling due to the novel function of moesin in controlling optimal surface abundance and stability of T $\beta$ RII, which would by all means have broader implications due to the well-established roles of TGF- $\beta$. Indeed, the reduction of surface T $\beta$ RII was also observed in $\mathrm{CD}^{+}$and $\mathrm{B} 22 \mathrm{O}^{+} \mathrm{B}$ cells (Figure $6, \mathrm{~A}^{-} \mathrm{C}$ ), thus not specific to the $\mathrm{CD} 4^{+} \mathrm{T}$ cell lineage. Nonetheless, these data are consistent and support our finding that moesin controls the abundance of T $\beta$ RII. Thus, it would be interesting to determine the role of this mechanism in other immune cells such as TGF- $\beta$-induced Th17 cells or innate lymphoid cells, Th9 or $\mathrm{T}$ follicular cells, or even B cells, which express higher T $\beta$ RII and also require TGF- $\beta$ for IgA class switching and other functions. Future work would use cell-specific Msn KO mice to decipher the contribution of moesin to various signal transduction pathways and impact on immunotherapy. Thus, it is envisaged that these initial findings would stimulate further in-depth studies of the ERM proteins in other immune components and as possible therapeutic targets to further advance our knowledge. We have uncovered a novel regulatory mechanism by which moesin controls the surface abundance of T $\beta$ RII to promote optimal TGF- $\beta$ signaling - in the context of iTregs, this mechanism provides signals required for their efficient generation. TGF- $\beta$ receptors are well documented to internalize and recycle for more potent signaling $(23,42)$, but the molecular nodules that control this process are less understood. The incomplete abrogation of surface T $\beta$ RII and TGF- $\beta$ signaling in Msn KO cells also suggests that other factors might be involved in the process. Although moesin is the dominant ERM protein in $\mathrm{T}$ cells compared with ezrin, it has been suggested that ezrin also regulates TGF- $\beta$ responses in epithelial cells during metastasis (47). In addition, the molecular requirements regulating the moesin-T $\beta$ RII interaction require in-depth studies. ERM proteins bind to the $\mathrm{C}$-terminal regions of their targets via the $\mathrm{N}$-terminal FERM domain, but further work is needed to identify the motifs involved for successful drug targeting. Our studies highlight several novel aspects of moesin as a regulator of TGF- $\beta$ signaling, via control of T $\beta$ RII, which appears to be a direct consequence of its function in the generation of iTregs - a property that can be harnessed for therapeutic targeting of moesin in adoptive $T$ cell therapy and immunotherapy combinations for the treatment of cancer.

\section{Methods}

Mice. C57BL/6 (CD45.1), Rag2-- mice were from The Jackson Laboratory. Moesin knockout (Msn KO) mice (CD45.2) were generated on a $129 \times$ C57BL/6 background via the conventional gene-trapping system (Texas A\&M Institute for Genomic Medicine, College Station, Texas, USA; Msn-OST432827). A retroviral gene trapping construct with a splicing acceptor site and stop codon was confirmed by PCR to insert 
to the first intron of the Msn gene, resulting in knockout of Msn mRNA. Mice were backcrossed to a C57BL/6 background for up to 8 generations for studies described here. All mice used for experiments were on the C57BL/6 background. In general, both male $\left(\mathrm{Msn}^{-/ Y}\right)$ and female $\left(\mathrm{Msn}^{--}\right)$moesin KO mice appeared healthy at birth and remained viable into adulthood. Notably, hemizygous knockout male mice $\left(\mathrm{Msn}^{-/ Y}\right)$ are fertile when mated with heterozygous females; in contrast, homozygous female knockout $\left(\mathrm{Msn}^{--}\right)$mice have delayed pregnancies and no successful births when mated with WT or $\mathrm{Msn}^{-/ Y}$ syngeneic males. Unless otherwise stated, 8- to 10-week-old age- and sex-matched littermate mice were used in all experiments. mBMCs (WT and Msn $\mathrm{KO}, 1: 1)$ were generated by transfer of $2 \times 10^{6}$ bone marrow cells of each indicated genotype into irradiated CD45.1 mice, allowing 8-10 weeks to reconstitute. Bone marrow chimeras were also generated by transfer of $2 \times 10^{6}$ bone marrow cells of either WT (CD45.1) or Msn KO (CD45.2) separately into irradiated WT-CD45.1 mice, allowing another 8-10 weeks to reconstitute. Notably, spleen and MLNs were kept separate throughout the study. Animals were bred and maintained in a specific pathogen-free barrier facility at the Medical University of South Carolina.

Antibodies and flow cytometry. Thymi, spleens, and MLNs were minced into single-cell suspensions in PBS containing 1\% FCS, and splenocytes were depleted of red blood cells with RBC lysis buffer (Sigma-Aldrich). Cell suspensions were incubated with mouse Fc Block (BD Biosciences). Cells were immediately stained for surface markers and intracellular molecules. Antibodies against CD4 (GK1.5), FOXP3 (FJK-16), Helios (22F6), MHCI (SF1-1.1), IL-4 (11B11), IFN- $\gamma$ (XMG1.2), TNF- $\alpha$ (Mp6-XT22), CD62L (MEL-14), CD39 (24DMS1), GARP (YGIC86), GITR (DTA-1), CD45 (PC61.5), and CD45.2 (clone 104) and $\mathrm{F}\left(\mathrm{ab}^{\prime}\right)_{2}$ anti-rabbit IgG were purchased from eBioscience; antibodies against PD-1 (J43), CD8 (53-6.7), B220 (RA3-6B2), CD44 (1M7), IL-17A (TC11-18H10), CTLA-4 (UC10-4F1011BD), and CD45.1 (A20) were obtained from BD Pharmingen. Antibodies against SMAD2 (pS465/pS467) and SMAD3 (pS423/pS425) (O72670) were obtained from BD Biosciences. Antibodies against moesin (Q480, Cell Signaling Technology), TRRII (ABOY0316011), and NRP1 (ABDX0114051) were from R\&D Systems. For intracellular cytokine staining, cells were stimulated for 4 hours with $50 \mathrm{ng} / \mathrm{ml}$ PMA (phorbol 12-myristate-13-acetate) and $1 \mu \mathrm{g} / \mathrm{ml}$ ionomycin (Sigma-Aldrich) in the presence of $5 \mu \mathrm{g} / \mathrm{ml}$ brefeldin A (BD Biosciences). Intracellular FOXP3 (FJK-16) was stained with the eBioscience FOXP3 staining buffer set (00-5523-00, eBioscience). Intracellular IL-17A and IFN- $\gamma$ were stained with BD Cytofix/Cytoperm (51-2090KZ, BD Biosciences). For detection of phosphorylated signaling molecules, cells were serum-starved for 1 hour for primary cells or overnight for EL4 cells in serum-free RPMI 1640. Cells were stimulated with TGF- $\beta$ (5 $\mathrm{ng} / \mathrm{ml}$, PeproTech) and fixed with Phosflow Lyse/Fix Buffer, followed by permeabilization with Phosflow Perm Buffer III (both from BD Biosciences), and stained with antibodies against pSMAD2/3-APC (1:40 dilution; BD Biosciences). Expression of surface and intracellular markers was analyzed with a flow cytometer (BD FACSVerse) and FlowJo software (Tree Star).

Polyribosome profiling. Polysome analysis was performed as described previously (12). Briefly, cell lysates were layered onto a $10 \%-50 \%$ sucrose gradient and centrifuged at $35,000 \mathrm{~g}$ at $4^{\circ} \mathrm{C}$ for 4 hours. Gradient fractions were collected using a fraction collector with continuous monitoring of absorbance at $254 \mathrm{~nm}$. RNA was extracted with Trizol (Invitrogen) and purified with RNeasy Mini Kit (Qiagen). Reverse transcription PCR (RT-PCR) or quantitative RT-PCR was performed with the following primers: Msn: forward, 5'-TGGATGCCTTGGGTCTCAAC-3'; reverse, 5'-CGCTTGTTAATCCGAAGCCG-3'; Dab2: forward, 5'-GGTCTAGGTACGGTCCCAGT-3'; reverse, 5'-CCAGACTTGTACTGCTGGGG-3'.

Generation of in vitro and in vivo inducible Tregs. Primary $\mathrm{CD} 4{ }^{+} \mathrm{CD} 25^{-} \mathrm{T}$ cells were isolated from the spleen of 8- to 10-weekold WT C57BL/6 (WT.B6) or moesin knockout (Msn KO) mice using MACS columns (Miltenyi Biotec). Purity of $\mathrm{CD} 4{ }^{+} \mathrm{CD} 25^{-} \mathrm{T}$ cells exceeding $95 \%$ was used in all in vitro iTreg generation and adoptive transfer experiments. For in vitro iTreg generation, cells were seeded at $1 \times 10^{6}$ per well in a 24-well plate and stimulated with $5 \mu \mathrm{g} / \mathrm{ml}$ of platebound anti-CD3 (145-2C11; BD Biosciences) and $2 \mu \mathrm{g} / \mathrm{ml}$ anti-CD28 (37.51; BD Biosciences) in complete medium (RPMI with $10 \%$ [vol/vol] FBS heat-inactivated and $100 \mathrm{U} / \mathrm{ml}$ of IL-2) with or without TGF- $\beta 1$ at 5-10 ng/ml. In all experiments, iTregs were generated in complete $\mathrm{T}$ cell medium supplemented with anti-IL-4 $(5 \mu \mathrm{g} / \mathrm{ml})$ and anti-IFN- $\gamma$ $(5 \mu \mathrm{g} / \mathrm{ml})$. T cells were incubated at $37^{\circ} \mathrm{C}$ in $5 \% \mathrm{CO}_{2}$, and then FOXP3 expression was analyzed on day 3 and/or day 5 . Th0 cells are defined as purified splenic primary $\mathrm{CD} 4^{+} \mathrm{CD} 25^{-} \mathrm{T}$ cells activated in the presence of anti-CD3 and anti-CD28 antibodies, but without TGF- $\beta$. For in vivoinduced Treg differentiation, primary $\mathrm{CD} 4^{+} \mathrm{CD} 25^{-} \mathrm{T}$ cells $\left(1 \times 10^{6}\right.$ cells per mouse) were isolated from the spleen of WT.B6 and adoptively transferred by i.v. injection into B6.Rag $2^{-/-}$mice. Splenic $\mathrm{CD}^{+}{ }^{+} \mathrm{FXP}^{+}$ $\mathrm{T}$ cells were isolated and analyzed by flow cytometry between 20 and 30 days after transfer.

Intestinal cell isolation. The small and large intestinal lamina propria were dissected and Peyer's patches excised. The lumen was cleaned by flushing with PBS and then minced. The resulting cell suspension was passed through a $40-\mu \mathrm{m}$ filter, and the isolated cells were incubated for 30 minutes at $37^{\circ} \mathrm{C}$ with collagenase D $(1 \mathrm{mg} / \mathrm{ml}$; Roche), dispase (0.05 U/ml; Worthington), and DNase I (100 mg/ $\mathrm{ml}$; Sigma-Aldrich). Lymphocytes were collected at the interface of a 40\%/80\% Percoll gradient (GE Healthcare). Cells were stained for surface markers, followed by fixation and permeabilization for intracellular staining of transcription factors (eBioscience). Stained cells were analyzed by flow cytometry.

Adoptive T cell transfer model of colitis. For adoptive transfer experiments, splenocytes from C57BL/6 mice were incubated with anti-CD25 MACS beads and depleted of CD25 cells using the MACS LD column (Miltenyi Biotec). A total of $5 \times 10^{5}$ sorted $\mathrm{CD} 4^{+} \mathrm{CD} 25^{-} \mathrm{CD} 45 \mathrm{RB}^{\mathrm{hi}}$ effector $\mathrm{T}$ cells per mouse, with or without $2 \times 10^{5} \mathrm{CD} 4^{+} \mathrm{CD} 25^{+} \mathrm{WT}$ or $\mathrm{Msn}$

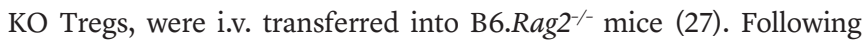
transfer, animals were monitored, and clinical evidence of disease such as the body weight loss and loose stool or diarrhea was recorded weekly. Mice were sacrificed 10 weeks after injection of cells, and organs, including colons, were examined histologically for evidence of colitis.

In vitro Treg functional assay. $\mathrm{CD} 4^{+} \mathrm{CD} 45 \mathrm{RB}^{\text {hi }} \mathrm{CD} 25^{-}$naive cells and $\mathrm{CD} 4{ }^{+} \mathrm{CD} 45 \mathrm{RB}^{\mathrm{lo}} \mathrm{CD} 25^{+}$Tregs were prepared from spleens and MLNs, underwent enrichment for $\mathrm{CD} 4^{+} \mathrm{T}$ cells as described above, and then were stained. Naive $\mathrm{CD} 4^{+} \mathrm{T}$ cells and Tregs were isolated by cell sorting. FACS-sorted $C D 4^{+} C D 45 \mathrm{RB}^{\text {hi }} \mathrm{CD} 25^{-}$responder $\mathrm{T}$ cells $\left(5 \times 10^{4}\right)$ were labeled with CFSE and then cultured for 72 hours with $\mathrm{CD} 4{ }^{+} \mathrm{CD} 45 \mathrm{RB}^{10} \mathrm{CD} 25^{+} \mathrm{WT}$ or Msn KO Tregs (at a ratio of $1: 1$ to $1: 8)$ or without Tregs after stimulation with anti-CD3 $(2 \mu \mathrm{g} / \mathrm{ml})$ in the presence of $1 \times 10^{5}$ irradiated splenocytes (30 Gy). 
The division of responding T cells was assessed by dilution of CFSE (Thermo Fisher Scientific).

Melanoma tumor model and $T$ cell persistence in moesin-deficient mice. WT or Msn KO mice were challenged s.c. with $2.5 \times 10^{5}$ B16-F1 tumor cells. Some mice were excluded before randomization for adoptive cell transfer (ACT) due to abnormal tumor growth. Mice were infused with 2 $\times 10^{6}$ Pmel-1 CD 8 cells (Pmel-1) as indicated by adoptive transfer via tail vein injection. In another experiment, B6.Rag2 ${ }^{-/}$tumor-bearing mice were coinfused with Pmel-1 CD8 $8^{+}$T cells together with WT or Msn KO $\mathrm{CD} 4^{+} \mathrm{CD} 25^{-} \mathrm{T}$ cells isolated from the spleen of bone marrow chimeras. Mice also received total-body irradiation (6 Gy) prior to adoptive $\mathrm{T}$ cell transfer. Tumor growth was monitored daily and measured by caliper every 2-4 days by personnel blinded to the genotype of the mice. In addition, peripheral blood lymphocytes or tumor infiltrate lymphocytes were stained for CD8 and Thy1.1 to identify donor T cells. Tumor size $\left(\mathrm{mm}^{2}\right)$ was calculated as length $\times$ width, and mice were sacrificed when tumors reached $300-400 \mathrm{~mm}^{2}$. Donor and recipient mice were gendermatched in all ACT experiments, and recipient mice were 8-12 weeks of age. All animals were housed under specific pathogen-free conditions in accordance with institutional and federal guidelines.

Lentiviral production and infection. Lentiviral particles were produced in HEK293FT cells according to standard protocols. Spleen-isolated primary $\mathrm{CD} 4^{+} \mathrm{CD} 25^{-} \mathrm{T}$ cells $\left(2 \times 10^{5}\right.$ cells per well $)$ were transduced with lentiviral supernatants. Murine lentiviral DNA plasmid against Msn (moesin) (sequence: CCGGTAGGATTTAGCCTCTTAATTACTCGAGTAATTAA GAGGCTAAATCCTATTTTTTG) (Sigma-Aldrich; TRC2-pLKO.1-puromycin) was transduced into $\mathrm{CD} 4^{+} \mathrm{T}$ cells activated for 48 hours with antiCD3 and anti-CD28 with Polybrene ( $8 \mu \mathrm{g} / \mathrm{ml}$; Sigma-Aldrich).

RNA isolation and quantitative RT-PCR. RNA was isolated and analyzed by quantitative RT-PCR with the following moesin primers using SYBR Green reagent: $M s n$ : forward, 5'-TGGATGCCTTGGGTCTCAAC-3'; reverse, 5'-CGCTTGTTAATCCGAAGCCG-3'; Foxp3: forward, 5'-CTGGACAACCCAGCCATGAT-3'; reverse, 5'-ACATTGATCCCAGGTGGCAG-3'; Dab2: forward, 5'-GGTCTAGGTACGGTCCCAGT-3'; reverse, 5'-CCAGACTTGTACTGCTGGGG-3'; Ilei: forward, 5'-GCTGCAAAGTTGGTAGTGGC-3'; reverse, 5'-CGCCTTTGAGATCCCACACT-3'; Tnf: forward, 5'-CATCTTCTCAAAATTCGAGTGACAA-3'; reverse， 5'-TGGGAGTAGACAAGGTACAACCC-3'; Ifng: forward, 5'-CTCTTCCTCATGGCTGTTTCT-3'; reverse, 5'-TTCTTCCACATCTATGCCACTT-3'.

RNA immunoprecipitation. Immunoprecipitations were performed with rabbit anti-hnRNP E1 antibody (5-10 $\mu \mathrm{g}$; EPR11055, Abcam) or rabbit IgG control (AB21-K, Millipore) and $50 \mu$ Protein A-Sepharose 4B beads (Thermo Fisher Scientific). Antibody and beads were incubated overnight at $4^{\circ} \mathrm{C}$ with up to $1 \mathrm{mg}$ of lysates prepared from ThO cells and iTregs with rotation, followed by washing 5 times in radioimmunoprecipitation assay (RIPA) lysis buffer. RNA was then isolated from the immunoprecipitated samples using Trizol according to the manufacturer's instructions, with the addition of glycogen (Thermo Fisher Scientific) at the isopropanol precipitation step to aid RNA recovery.

Immunoblotting. $\mathrm{T}$ cells were stimulated under ThO or iTreg conditions as described above. Th0 cells are defined as naive CD4 ${ }^{+}$ $\mathrm{T}$ cells activated in the presence of anti-CD3/anti-CD28 antibodies and IL-2, but without TGF- $\beta 1$, and maintained in complete T cell medium. Cells were harvested on day 3 or 5 , and then counted and washed with cold serum-free RPMI 1640 medium. Collected cells were lysed with RIPA buffer containing protease and phosphatase inhibitors, and prepared for SDS-PAGE. For immunoblotting, PVDF membranes were blocked at room temperature for 1 hour with $6 \%$ nonfat milk blocking buffer and then probed with rabbit anti-moesin (Q480, Cell Signaling Technology); rat anti-FOXP3 (FJK-16s, eBioscience); rabbit anti-TßRII (sc-400), normal rabbit IgG (sc-2027), normal mouse IgG (sc-2025) (Santa Cruz Biotechnology); rabbit anti-Akt2 (phospho-S474, ab38513), rabbit anti-pSMAD3 (ab73942), rabbit antiSMAD3 (phospho-S423+S425, EP823Y), or rabbit anti-GFP (ab290) (Abcam); or mouse anti-HA.11 (16B12, BioLegend). Secondary antimouse (A8924), anti-rat (A5795), and anti-rabbit (A0545) IgG-HRP antibodies were obtained from Sigma-Aldrich.

Cell lines, expression constructs, and transfection. EL4 LAF cells (gift from Yukiko Tone and Masahide Tone, Cedars-Sinai, Los Angeles, California, USA) were described previously (22). HEK293FT and B16-F1 cells were purchased from the ATCC. Constructs for the expression of Msn and Tgfbr 2 were generated from human cDNA. Msn tagged with cyan fluorescent protein (CFP) at the carboxyl terminus was expressed via the vector $\mathrm{pD} 311-\mathrm{CFP}$; TGF $\beta$ RII tagged with HA at the carboxyl terminus was expressed via pCMV5B vector (obtained from Addgene) (48). HEK293FT cells were transfected through the use of Lipofectamine 2000 Transfection Reagent (Life Technologies), and cells were harvested 36 hours after transfection.

Statistics. Data are presented as mean \pm SEM unless otherwise stated. Statistical significances were determined by the unpaired 2-tailed Student's $t$ test, 2-way ANOVA, and log-rank test and by the Wilcoxon signed-rank nonparametric test where specified using GraphPad Prism software, version 5.0 (GraphPad Prism Software). ${ }^{* *} P$ less than 0.001, ${ }^{* *} P$ less than 0.01 , and ${ }^{*} P$ less than 0.05 were considered to be statistically significant.

Study approval. All animal experiments were performed using approved protocols and in accordance with the guidelines of the Medical University of South Carolina. Animal experiments were approved by the Institutional Animal Care and Use Committee regulations at Medical University of South Carolina.

\section{Author contributions}

EAAA and ZL conceived the project and prepared the manuscript. EAAA designed and performed experiments and analyzed the data. YZ performed experiments and quantifications. YY, GSH, $\mathrm{BVH}$, and $\mathrm{BL}$ performed experiments and provided valuable input on the manuscript. MS and BR provided help with experiments. SS analyzed histological data. DCR, SK, and $\mathrm{PHH}$ provided reagents as well as suggestions and discussions throughout the study. ZL supervised the study and was involved in the design and evaluation of all experiments.

\section{Acknowledgments}

We thank all members of the laboratory, especially Caroline Wallace. We thank Alan Diehl, Chrystal Paulos, and Michelle Nelson for helpful inputs during the course of this study and for critical review of the manuscript, and the Cancer Immunology Program at the Hollings Cancer Center for stimulating discussions. This work was supported by the NIH (R01DK098819 to DCR; U01AI12585 to YY; P01CA186866, R01CA188419, and R01AI070603 to ZL), and by the Flow Cytometry \& Cell Sorting Unit and the Cell \& Molecular Imaging Shared Resource, Hollings Cancer Center, 
Medical University of South Carolina (P30CA138313). ZL is the Abney Chair Remembering Sally Abney Rose in Stem Cell Biology \& Therapy and was supported by the SmartState Endowed Chair Program of South Carolina.
Address correspondence to: Zihai Li, Department of Microbiology and Immunology, Hollings Cancer Center, Medical University of South Carolina, 86 Jonathan Lucas Street, Charleston, South Carolina 29425, USA. Phone: 843.792.1034; E-mail: Zihai@musc.edu.
1. Fehon RG, McClatchey AI, Bretscher A. Organizing the cell cortex: the role of ERM proteins. Nat Rev Mol Cell Biol. 2010;11(4):276-287.

2. Fernando H, Martin TA, Douglas-Jones A, Kynaston HG, Mansel RE, Jiang WG. Expression of the ERM family members (ezrin, radixin and moesin) in breast cancer. Exp Ther Med.2010;1(1):153-160.

3. Chakraborty PK, et al. G protein-coupled receptor kinase GRK5 phosphorylates moesin and regulates metastasis in prostate cancer. Cancer Res. 2014;74(13):3489-3500.

4. Abiatari I, et al. Moesin-dependent cytoskeleton remodelling is associated with an anaplastic phenotype of pancreatic cancer. J Cell Mol Med. 2010;14(5):1166-1179.

5. Estecha A, et al. Moesin orchestrates cortical polarity of melanoma tumour cells to initiate 3D invasion. JCell Sci. 2009;122(pt 19):3492-3501.

6. Shcherbina A, Bretscher A, Kenney DM, RemoldO'Donnell E. Moesin, the major ERM protein of lymphocytes and platelets, differs from ezrin in its insensitivity to calpain. FEBS Lett. 1999;443(1):31-36.

7. Hirata $\mathrm{T}$, et al. Moesin-deficient mice reveal a non-redundant role for moesin in lymphocyte homeostasis. Int Immunol. 2012;24(11):705-717.

8. Fontenot JD, Dooley JL, Farr AG, Rudensky AY. Developmental regulation of Foxp3 expression during ontogeny.JExp Med.2005;202(7):901-906.

9. Chen W, et al. Conversion of peripheral $\mathrm{CD}^{+} \mathrm{CD} 25^{-}$naive $\mathrm{T}$ cells to $\mathrm{CD} 4^{+} \mathrm{CD} 25^{+}$regulatory T cells by TGF- $\beta$ induction of transcription factor Foxp3. JExp Med. 2003;198(12):1875-1886.

10. Moustakas A, Heldin CH. Non-Smad TGF- $\beta$ signals. J Cell Sci. 2005;118(pt 16):3573-3584.

11. Gorelik L, Flavell RA. Transforming growth factor- $\beta$ in T-cell biology. Nat Rev Immunol. 2002;2(1):46-53.

12. Chaudhury A, Hussey GS, Ray PS, Jin G, Fox PL, Howe PH. TGF- $\beta$-mediated phosphorylation of hnRNP E1 induces EMT via transcript-selective translational induction of Dab2 and ILEI. Nat Cell Biol. 2010;12(3):286-293.

13. Hussey GS, et al. Identification of an mRNP complex regulating tumorigenesis at the translational elongation step. Mol Cell. 2011;41(4):419-431.

14. Hussey GS, Link LA, Brown AS, Howley BV, Chaudhury A, Howe PH. Establishment of a TGF $\beta$-induced post-transcriptional EMT gene signature. PLoS One. 2012;7(12):e52624.

15. Quintana FJ, et al. Control of T(reg) and $\mathrm{T}(\mathrm{H}) 17$ cell differentiation by the aryl hydrocarbon receptor. Nature. 2008;453(7191):65-71.

16. Polansky JK, et al. Methylation matters: binding of Ets-1 to the demethylated Foxp3 gene contributes to the stabilization of Foxp3 expression in regulatory T cells. J Mol Med.2010;88(10):1029-1040.

17. Jain N, et al. Cutting edge: Dab2 is a FOXP3 target gene required for regulatory $\mathrm{T}$ cell function. JImmunol. 2009;183(7):4192-4196.
18. Brown AS, Mohanty BK, Howe PH. Computational identification of post translational modification regulated RNA binding protein motifs. PLOS ONE. 2015;10(9):e0137696.

19. Coombes JL, et al. A functionally specialized population of mucosal $\mathrm{CD} 103^{+}$DCs induces Foxp $3^{+}$regulatory T cells via a TGF- $\beta$ and retinoic acid-dependent mechanism. J Exp Med. 2007;204(8):1757-1764.

20. Elkord E, Al-Ramadi BK. Helios expression in FoxP3(+) T regulatory cells. Expert Opin Biol Ther. 2012;12(11):1423-1425.

21. Ruan Q, et al. Development of Foxp3(+) regulatory $t$ cells is driven by the c-Rel enhanceosome. Immunity. 2009;31(6):932-940.

22. Tone Y, Furuuchi K, Kojima Y, Tykocinski ML, Greene MI, Tone M. Smad3 and NFAT cooperate to induce Foxp3 expression through its enhancer. Nat Immunol. 2008;9(2):194-202.

23. Vizan P, Miller DS, Gori I, Das D, Schmierer B, Hill CS. Controlling long-term signaling: receptor dynamics determine attenuation and refractory behavior of the TGF- $\beta$ pathway. Sci Signal. 2013;6(305):ra106.

24. Nomachi A, et al. Moesin controls clathrin-mediated S1PR1 internalization in T cells. PLoS One. 2013;8(12):e82590.

25. Nakamura F, Huang L, Pestonjamasp K, Luna EJ, Furthmayr H. Regulation of F-actin binding to platelet moesin in vitro by both phosphorylation of threonine 558 and polyphosphatidylinositides. Mol Biol Cell. 1999;10(8):2669-2685.

26. Zhu L, et al. High turnover of ezrin T567 phosphorylation: conformation, activity, and cellular function. Am J Physiol Cell Physiol. 2007;293(3):C874-C884.

27. Zhang Y, et al. GP96 is a GARP chaperone and controls regulatory $\mathrm{T}$ cell functions. JClin Invest. 2015;125(2):859-869.

28. Dannull J, et al. Enhancement of vaccinemediated antitumor immunity in cancer patients after depletion of regulatory T cells. JClin Invest. 2005;115(12):3623-3633.

29. Rubinstein MP, et al. Ex vivo interleukin-12-priming during $\mathrm{CD} 8(+) \mathrm{T}$ cell activation dramatically improves adoptive $\mathrm{T}$ cell transfer antitumor efficacy in a lymphodepleted host. J Am Coll Surg. 2012;214(4):700-707.

30. Barroso-González J, Machado JD, García-Expósito L, Valenzuela-Fernández A. Moesin regulates the trafficking of nascent clathrin-coated vesicles. J Biol Chem. 2009;284(4):2419-2434.

31. Vitorino P, et al. MAP4K4 regulates integrinFERM binding to control endothelial cell motility. Nature. 2015;519(7544):425-430.

32. Harrington JR. Chemokines induce moesin interaction with ICAM-3. Oncologist. 2000;5(1):75-76.

33. Shaffer MH, et al. Ezrin and moesin function together to promote $\mathrm{T}$ cell activation. J Immunol. 2009;182(2):1021-1032.
34. Shevach EM, Davidson TS, Huter EN, Dipaolo RA, Andersson J. Role of TGF- $\beta$ in the induction of Foxp3 expression and $\mathrm{T}$ regulatory cell function. JClin Immunol. 2008;28(6):640-646.

35. Huber $S$, et al. Cutting edge: TGF- $\beta$ signaling is required for the in vivo expansion and immunosuppressive capacity of regulatory $\mathrm{CD} 4^{+} \mathrm{CD} 25^{+} \mathrm{T}$ cells. JImmunol. 2004;173(11):6526-6531.

36. Gorelik L, Flavell RA. Immune-mediated eradication of tumors through the blockade of transforming growth factor-beta signaling in $\mathrm{T}$ cells. Nat Med. 2001;7(10):1118-1122.

37. Pircher A, et al. Neoadjuvant chemo-immunotherapy modifies $\mathrm{CD} 4(+) \mathrm{CD} 25(+)$ regulatory $\mathrm{T}$ cells (Treg) in non-small cell lung cancer (NSCLC) patients. Lung Cancer. 2014;85(1):81-87.

38. Gandhi $\mathrm{R}$, et al. Activation of the aryl hydrocarbon receptor induces human type 1 regulatory T cell-like and Foxp3(+) regulatory T cells. Nat Immunol. 2010;11(9):846-853.

39. Carmeci C, Thompson DA, Kuang WW, Lightdale N, Furthmayr H, Weigel RJ. Moesin expression is associated with the estrogen receptornegative breast cancer phenotype. Surgery. 1998;124(2):211-217.

40. Kinoshita T, et al. Tumor suppressive microRNA-133a regulates novel targets: moesin contributes to cancer cell proliferation and invasion in head and neck squamous cell carcinoma. Biochem Biophys Res Commun. 2012;418(2):378-383.

41. Li X, et al. MiR-200 can repress breast cancer metastasis through ZEB1-independent but moesin-dependent pathways. Oncogene. 2014;33(31):4077-4088.

42. Di Guglielmo GM, Le Roy C, Goodfellow AF, Wrana JL. Distinct endocytic pathways regulate TGF- $\beta$ receptor signalling and turnover. Nat Cell Biol. 2003;5(5):410-421.

43. Ramel D, Wang X, Laflamme C, Montell DJ, Emery G. Rab11 regulates cell-cell communication during collective cell movements. Nat Cell Biol. 2013;15(3):317-324.

44. Bandyopadhyay B, et al. T $\beta$ RI/Alk5-independent TRRII signaling to ERK1/2 in human skin cells according to distinct levels of T $\beta$ RII expression. JCell Sci. 2011;124(pt 1):19-24.

45. Okayama T, et al. Attenuated response to liver injury in moesin-deficient mice: impaired stellate cell migration and decreased fibrosis. Biochim Biophys Acta. 2008;1782(9):542-548.

46. Chen YX, et al. Role of moesin in renal fibrosis. PLoS One. 2014;9(11):e112936.

47. Chen MJ, Gao XJ, Xu LN, Liu TF, Liu XH, Liu LX. Ezrin is required for epithelial-mesenchymal transition induced by TGF- $\beta 1$ in A 549 cells. Int $J$ Oncol. 2014;45(4):1515-1522.

48. Wrana JL, et al. TGF beta signals through a heteromeric protein kinase receptor complex. Cell. 1992;71(6):1003-1014. 